\title{
Study of adolescents: Dynamics of perception, attitude, knowledge and use of reproductive health care
}

Syed Jahangeer Haider

Shamsun Nehar Saleh

Nahid Kamal

Alan Gray

Follow this and additional works at: https://knowledgecommons.popcouncil.org/departments_sbsr-pgy

Part of the Family, Life Course, and Society Commons, and the International Public Health Commons How does access to this work benefit you? Let us know!

\section{Recommended Citation}

Haider, Syed Jahangeer, Shamsun Nehar Saleh, Nahid Kamal, and Alan Gray. 1997. "Study of adolescents: Dynamics of perception, attitude, knowledge and use of reproductive health care." Dhaka: Population Council. 
Study of

Adolescents:

Dynamics

of Perception,

Attitude,

Knowledge

and Use of Reproductive Health Care
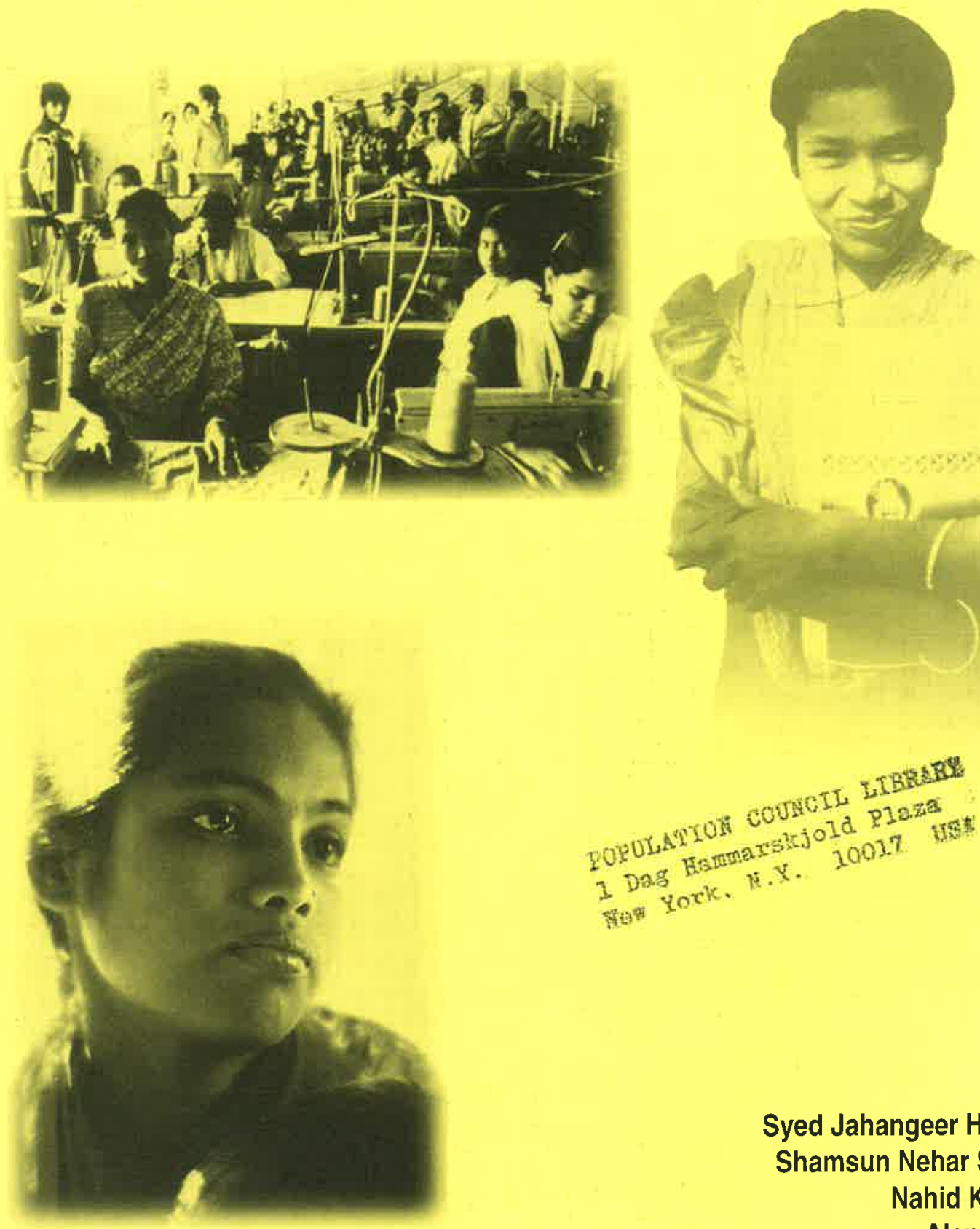

Syed Jahangeer Haider

Shamsun Nehar Saleh

Nahid Kamal

Alan Gray 


\title{
Study of Adolescents: Dynamics of Perception, Attitude, Knowledge and Use of Reproductive Health Care
}

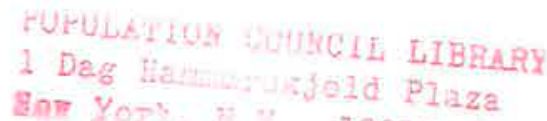 \\ Syed Jahangeer Haider, Dr. P. H.* \\ Shamsun Nehar Saleh* \\ Nahid Kamal \\ Alan Gray, Ph.D.
}

10017 TSA

A collaborative project between Population Council and Research Evaluation Associates for Development (READ)*

June, 1997 
Copyright ${ }^{\circledR}$ 1997, Population Council, Bangladesh

This is one of a series of studies conducted by Population Council, Bangladesh, under the 'Strengthening Population Policy and Research Capacity Project', for USAID, Dhaka, Cooperative Agreement No. CCP3050-A-00-4013-00

Published by Population Council, Dhaka, Bangladesh

PO Box 6016, Gulshan, Dhaka 1212

(House CES(B) 21, Road 118, Gulshan)

Telephone (880-2) 881227, 886657, Fax 883127, 883132

Email: PCDHAKA@POPCOUNCIL.ORG

Printed by Karshaf Printers (Pvt) Ltd.

Recommended citation:

Haider, Syed Jahangeer; Saleh, Shamsun Nehar; Kamal, Nahid; Gray, Alan; 1997, Study of Adolescents: Dynamics of Perception, Attitude, Knowledge and Use of Reproductive Health Care, Dhaka: Population Council 


\section{Preface}

The background to this Project was a concern that Bangladesh relies heavily on a handful of contract research organizations to generate most of its population data, and in many cases to provide population policy guidance to the Government. A more desirable situation would be that the country has a number of stable research institutions with well trained researchers capable of conducting policy relevant research for the Government and others.

The objective of the Project then, has been to provide the opportunity to a group of less experienced researchers to gain experience by participating in a number of studies under the guidance of more experienced researchers. In addition to their involvement in every step of the research process, from study design and questionnaire development, through the fieldwork and data collection phase, to writing the final report, these researchers have received formal training in data collection, data analysis, presentation techniques, and other aspects of research from the hands of the senior members of the Project.

In addition to the above mentioned objective of building policy research capacity, a further objective was to make the studies relevant in their own right. For this reason all the studies were designed to focus on issues of current importance as the whole field of population research is evolving to include broader aspects of reproductive health. The titles of the five studies reflect this emphasis:

(i) Opportunities for Integration of RTI/STD Services into the FP-MCH Program.

(ii) Strengthening STD Services for Men in an Urban Clinic Based Program.

(iii) Study of Adolescents: Dynamics of Perceptions, Attitudes, Knowledge, and Use of Reproductive Health Care.

(iv) Traditional Family Planning in Bangladesh.

(v) Increasing the Financial Sustainability of Family Planning Service Delivery in Bangladesh

The completion of these five studies from recruitment of the research staff through the initial design, to the production of the final study reports, has taken place over the past twelve to eighteen months. Needless to say this has been a period of intense activity, but we hope the readers will consider the products to be worthwhile.

While, we believe this Project has contributed to the building of the research capacity of our team, there remains the issue of building research institutions for researchers to function in. We encourage the Government, the development partners, and our fellow researchers to continue to strive to achieve this important goal.

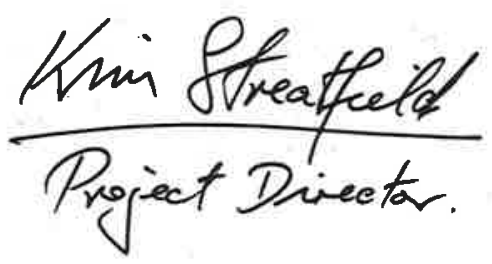




\section{CONTENTS}

Page

List of Tables

Acknowledgment

List of Abbreviations

Executive Summary

vi

vii

ix

$\mathrm{xi}$

*Chapter 1 : Introduction

1.1 Rationale and Importance 2

$\begin{array}{lll}1.2 & \text { Objectives } & 2\end{array}$

*Chapter 2 : Research Design and Methodologies 3

2.1 Study Design 3

2.2 Study Sample: Areas and Size 3

2.3 Data Collection and Instruments 4

2.4 Constraints Encountered During Data Collection 5

*Chapter 3 : Survey Design 7

$\begin{array}{lll}3.1 & \text { Focus of the Paper } & 7\end{array}$

$\begin{array}{ll}3.2 \text { Sample and Distribution } & 7\end{array}$

Chapter 4 : Findings and Discussions 11

* 4.1 Socio-Economic and Demographic Characteristics 11

* 4.2 Media Exposure $\quad 13$

\# 4.3 Sexuality 14

* 4.4 Reproductive Health 22

$\$ 4.5$ Marriage $\quad 26$

$\$ 4.6$ Fertility 28

$\$ \quad 4.7$ Use of Family Planning $\quad 29$

@ 4.8 MCH Care 33

@ 4.9 Women's Empowerment 35

Chapter 5 : Policy Implications and Interventions 39

$\begin{array}{ll}\text { References } & 43\end{array}$

* S.J. Haider \& S.N. Saleh

$\$ \quad$ Nahid Kamal

\# S.J.Haider \& Alan Gray

@ S.J. Haider \& Nahid Kamal 


\section{LIST OF TABLES}

\section{CHAPTER 3}

Table 1 Distribution of sample by areas and categories of respondents: for survey data collection with adolescents and husbands

Table 2 Distribution of FGD sample by respondents and geographical classifications

Table 3 Distribution of the guardians, community leaders and the service providers

Table 4 Distribution of the intensive (qualitative) interviews

\section{CHAPTER 4}

Table 5 \% Distribution of the adolescents and husbands by exposure to mass media on a regular basis

Table 6 Experience of Premarital Sexual Intercourse, by Marital Status, Age and Rural or Urban Residence

Table 7 Extramarital Sexual Experience of Husbands of Adolescent Women, by Duration of Marriage and Location

Table 8 Adolescent Women and Prior Knowledge about Menstruation, by Marital Status, Source of Information and Location

Table 9 Appropriate Sources for Sex Education

Table 10 Recommended Sources of Sex Education by Service Providers, Guardians and Community Leaders (\%)

Table 11 Distribution of respondents by correct knowledge of one or more symptoms of STD, RTI and AIDS

Table 12 Distribution of respondents by status of giving one or more correct responseon the process of transmission of STD, RTI and AIDS

Table 13 Distribution of respondents by status of giving correct or no response on the measures of prevention from STDs, RTI and AIDS

Table 14 Distribution of the guardians, community leaders and service providers by status of knowledge on transmission of STDs, RTIs and AIDS, Yes: Know the reason and NO: Don't Know the reason

Table 15 Distribution of adolescents and husbands by prevalence of symptoms of STDs and RTIs

Table 16 Distribution of age at marriage by geographical/socio-economic status

Table 17 Ideal age difference between husband and wife

Table 18 Distribution of pregnancy outcomes among married adolescents

Table 19 Distribution of respondents' knowledge by name of family planning methods

Table 20 Distribution of married females aged 15-19 by current use of family planning

Table 21 Distribution of family planning use by duration of marriage

Table 22 Distribution (\%) of Female Married Adolescents by Type of Birth Attendant during Delivery

Table 23 Distribution of the respondents by frequencies of observation of the incidents of violence against women 


\section{ACKNOWLEDGMENT}

The study of adolescents' sexuality and reproductive health was designed and implemented by Research Evaluation Associates For Development (READ) with technical assistance from the Population Council. Dr. Kim Streatfield, Country Representative, Population Council, Bangladesh rendered professional support through his advice and monitoring of the study. The Population Council also engaged a young professional, Ms. Nahid Kamal, who along with Ms. Shamsun Nehar Saleh, the lead professional of READ, was engaged in providing supervisory support to the study. READ also acknowledges the support provided by the USAID Mission in Bangladesh. We certainly appreciate the support from the Ministry of Health and Family Welfare including those from the Director Generals of Health, and Family Planning on program management during data collection. The foremost recognition for their invaluable services on data collection are due to the male and female investigators of READ, who despite formidable impediments, successfully completed data collection for the study.

Finally, we acknowledge the services rendered by Mr. Shahinul Islam and other technical/support staff at Population Council, whose cooperation and secretarial support were instrumental for the completion of the study.

Dr. Syed Jahangeer Haider

Principal Investigator

24 June 1997 


\section{LIST OF ABBREVIATIONS}

AIDS

ANC

ARI

BBS

BCG

CAR

CPR

CSW

$\mathrm{Cu}-\mathrm{T}$

DGHS

DGO

DHS

DPT

EC

ENC

EOC

EPI

FC

FP

FP-MCH

FPA

FPI

FW

FWA

FWC

FWV

GOB

HA

HDS

HIV

ICPD

IEC

IEDCR

IEM

IMR

IUD

$\mathrm{MCH}$

MCHTI

MCWC

MMR
: Acute Immune Deficiency Syndrome

: Ante Natal Care

: Acute Respiratory Infection

: Bangladesh Bureau of Statistics

: Bacille Calmette-Guerin (Tuberculosis vaccine)

: Contraceptive Acceptance Rate

: Contraceptive Prevalence Rate

: Commercial Sex Worker

: Copper-T

: Directorate General of Health Services

: Diploma in Gynaecology \& Obstetrics

: Demographic and Health Survey

: Diphtheria, Pertussis, Tetanus vaccine

: Eligible Couple

: Essential/Emergency Neonatal Care

: Essential/Emergency Obstetrics Care

: Expanded Program on Immunization

: Fertile Couple

: Family Planning

: Family Planning Maternal and Child Health

: Family Planning Assistant

: Family Planning Inspector

: Field Worker

: Family Welfare Assistant

: Family Welfare Center

: Family Welfare Visitor

: Government of Bangladesh

: Health Assistant

: Health and Demographic Survey

: Human Immune Deficiency Virus

: Integrated Community Program for Development

: Information, Education and Communication

$\therefore$ Institute of Epidemiology and Disease Control Research

: Information Education and Motivation

: Infant Mortality Rate

: Intra Uterine Device

: Maternal and Child Health

: Maternal and Child Health Training Institute

: Maternal and Child Welfare Center

: Maternal Mortality Rate 


$\begin{array}{lll}\text { MOHFW } & : & \text { Ministry of Health and Family Welfare } \\ \text { MR } & : & \text { Menstrual Regulation } \\ \text { MWRA } & : & \text { Married Women of Reproductive Age } \\ \text { NGO } & : & \text { Non-Government Organization } \\ \text { OBS \& GYN } & : & \text { Obstetrics \& Gynaecology } \\ \text { ORS } & : & \text { Oral Rehydration Saline } \\ \text { PHC } & : & \text { Primary Health Care } \\ \text { PHO } & : & \text { Population Health Office } \\ \text { PNC } & : & \text { Post Natal Care } \\ \text { READ } & : & \text { Research Evaluation Associates for Development } \\ \text { RH } & : & \text { Reproductive Health } \\ \text { RTI } & : & \text { Reproductive Tract Infection } \\ \text { RVF } & : & \text { Recto-vaginal Fistula } \\ \text { SC } & : & \text { Satellite Clinic } \\ \text { STD } & : & \text { Sexually Transmitted Disease } \\ \text { TB } & : & \text { Tuberculosis } \\ \text { TBA } & : & \text { Traditional Birth Attendant } \\ \text { THC } & : & \text { Thana Health Complex } \\ \text { THFPO } & : & \text { Thana Health \& Family Planning Officer } \\ \text { TT } & : & \text { Tetanus Toxoid vaccine } \\ \text { UNFPA } & : \text { United Nations Fund for Population Activities } \\ \text { UNICEF } & : \text { United Nations Children's Fund } \\ \text { UTI } & : & \text { Urinary Tract Infection } \\ \text { VAC } & : \text { Vitamin A Capsules } \\ \text { Vit-A } & : \text { Vitamin-A } \\ \text { VVF } & : \text { Vesico-vaginal Fistula } \\ \text { WB } & : \text { World Bank } \\ \text { WHO } & : \text { World Health Organization } \\ & & \end{array}$




\section{EXECUTIVE SUMMARY}

The integral relationship between family planning and the larger issues of reproductive health, education, status of women and development was pointed out at the ICPD Conference in Cairo. Knowledge of reproductive health and sexual attitudes and behavior is important to family planning researchers, policy makers and service providers, because these underlie virtually all the conditions that their programs address. However, little is known about how the adolescents interpret their sexual and reproductive lives and what providers can do to help them gain more effective control over their reproductive and sexual lives. Adolescents aged 15-19 constitute a large proportion ( 9 percent) of the Bangladesh population; and many of them are married.

The study was undertaken by Research Evaluation Associates For Development (READ) with support from the Population Council. The major objectives were to assess the level of knowledge, attitudes and practices of the adolescents on reproductive health including FP-MCH and sexuality. Selection of the sample for the study was done following multi-stage stratified random sampling at the thana level and below (unions and villages), while the districts and the urban locations (cities) were taken purposively. The study sample adequately covered all the regions of the country with representation of urban and rural areas and the population of varied socio-economic status (poor/slums and well off/colonies). The study does not furnish any national rates. However, the sample size of the adolescents, 1,860, was large enough to generalize the findings for designing future program interventions.

The primary focus of the study was adolescents (15-19 years), married and unmarried. The study also included sub-samples of husbands, guardians, community leaders and the service providers, who have an important influence on the adolescents. The data were collected through multiple instruments, including FGDs (14 sessions) and intensive, qualitative interviews (218) besides the main survey. This facilitated comparisons of data engendering data reliability. Both FGD and survey samples included married as well as unmarried adolescents, within the age range 15-19 years, and the husbands of the female married adolescents.

Findings have been analyzed comparing the data obtained through different techniques and also by varied respondent characteristics: i. urban samples in the (a) housing estates/colonies and (b) slums; and ii. rural samples in the (c)well-off and (d) poor sections. The mean age of the female and male adolescents ranged between 16 to 18 years, while the mean age of the husbands was 25-27 years. The overwhelming majority of the unmarried adolescents living in urban and rural areas completed education at grade six and above, with the exception of the adolescents in the slums. The level of education of the married adolescents was uniformly lower than their unmarried counterparts of varying backgrounds.

Three-fourths of the guardians were parents, of whom 42 percent were fathers and 33 percent mothers. The mean age of the parents and that of the in-laws were comparable (52 years). The majority of the community leaders representing the economically well-off backgrounds had completed grade 12 or above education. Half of the community leaders from slums and a quarter from the poor section in the rural areas completed the same level of education. Television, followed by radio, were the most popular media of mass communication for the adolescents. A very large proportion of the female unmarried adolescents both in the urban colonies ( 81 percent) and among the rural well-off population (74 percent) reported regular television viewing. 
The study observed high rates of pre-marital sex among the male unmarried adolescents while the husbands also reported high levels of both pre and extra-marital sex. These findings were comparable between surveys and intensive interviews. However, the married females, both during FGDs and survey interviews, were less likely to reveal their sexual experiences. There was evidence of pre-marital sex among the unmarried female adolescents.

In general, one-fifth to one-sixth of the adolescents demonstrated knowledge on STD, RTI and AIDS (symptoms, transmission and prevention). The findings of the FGDs and surveys in this regard were comparable. However, FGDs revealed that the respondents were also victims of serious misinformation. The knowledge of the service providers on STD, RTI and AIDS was observed to be better than that of the guardians and the community leaders. The adolescents in the rural and urban areas recommended sex education through various sources and the males preferred mass media while females preferred more personal transmission of information.

According to the female unmarried and married adolescents, the mean ideal age at marriage was 19.8 and 19.3 years, respectively. The actual female mean age at first marriage for this study group was 15 years, which gives a gap of 4 years between the actual and ideal age at first marriage. Although the sample did not include women aged more than 19 years, this indicates that there is still considerable social pressure on girls to get married at an early age. Sixteen percent of the study sample said that they were pregnant at the time of the interview. The rate of fetal wastage among adolescents, estimated using this study results, is about 10 percent which seems rather low. The average for the country is 12 percent or 120.1 per 1000 pregnancies (Demographic Surveillance System, MATLAB, 1994). The actual mean age at first birth was 16.0 years for married adolescents aged 15-19 in the study. The mean ideal spacing between marriage and first birth was 3.6 years although there were variations by marital status. About 30 percent of these married adolescents were aged between 12 and 15 at the time of the first delivery/birth. Services for delivery (child birth) are predominantly handled by the untrained and traditional providers. Only one-third of the married adolescents in urban housing colonies reported using trained care for delivery/childbirth, while it is between 8 and 11 percent for the other geographic/socio-economic classifications. In order to delay the first birth, the age at first marriage has to be increased.

It is interesting that although the level of knowledge on FP methods is low among the respondents in this study, the contraceptive prevalence rate (CPR) for the age group 1519 is much higher than the 1993-94 DHS results, 42.5 percent compared with 24.7 percent.

Between half and three-quarters of the adolescents reported that they had observed cases of violence against women. The most frequent reasons for violence against women, cited by the adolescents were dowry and marital problems.

Unless the adolescents are informed about reproductive processes, sexual intercourse, consequences of unsafe sex, early marriage and early births, the prospect for future healthy reproductive life for them is threatened. A considerable gap exists between the policies the government has proclaimed, and presumably committed themselves to, and the reality of women's lives. Women's reproductive health and status are influenced by several inter-related factors. It is, therefore, imperative to act simultaneously in several sectors to bring about changes in women's including adolescents' lives and their health. 


\section{CHAPTER 1}

\section{Introduction}

\subsection{RATIONALE AND IMPORTANCE}

The integral relationship between family planning and the larger issues of reproductive health, education, status of women and development was pointed out at the 1994 ICPD Conference in Cairo. Adolescents aged between 10-19 are a priority target for ensuring subsequent growth and development of sound reproductive health for the adult males and females. Major events like menarche, coital experiences, marriage, access to critical health behavior (FP/MCH and $\mathrm{PHC}$ ), enrollment in schools and exposure to vocational/occupational skills for socio-economic enhancement, occur during the adolescent period. Increasing access to quality FP services, providing more effective information on reproductive health, and increasing educational and employment opportunities for women and girls, will accelerate contraceptive prevalence and lower population growth rates. Reproductive health care should include FP information and services, pre and post natal care, prevention and treatment of sexually transmitted diseases (STD) and reproductive tract infections (RTI), education on AIDS, human sexuality, sexual and reproductive health, and responsible parenthood (Zeidenstein and Moore, 1996).

\subsubsection{Current Status of Adolescents}

The estimated adolescent population was 23 percent of the total population of Bangladesh in January, 1995, which accounts for 27 million of the country's population (Hossain, 1996). Of the total adolescent population (defined by Hossain to be all persons aged 10-19), 13 million are girls and 14 million boys. Twenty one percent (5.7 million) live in the urban and 79 percent ( 21.3 million) in the rural areas. Of the total population in Bangladesh, 13.7 percent are in the age range 10-14 and 9 percent between 15 and 19 (10.7 million). Of the 10.7 million adolescent population within the age range 15-19, 5.2 million are female, of whom 2.6 million ( 50 percent) are ever married; and 5.5 million are male, of whom 0.36 million (6.5 percent) are ever married (1991 Census and Hossain, 1996).

A study conducted by PDEU, (IMED) with a total of 1,941 married adolescent women under 20 years of age, observed that 97.7 percent were currently married, while the remaining 2.3 percent were either widowed or divorced (BBS report, 1996). Nearly 15 percent of the females claimed to have married at age 12 or less, 57 percent by age 14 and 74 percent by age 15. The mean age at first marriage among the married adolescents was found to be 14.3 years. The average age at first menstruation was 12.9 years. Nearly 20 percent of the respondents were married before they attained menarche.

About one-quarter ( 27 percent) of all the teenage girls in Bangladesh are mothers and another 6 percent are pregnant with their first child (Hossain, 1996). Thus one in three teenage girls has begun child bearing. There has been a slight decline in this proportion over time; data from the 1991 CPS indicate that in that year 36 percent of teenage girls had either given birth 
or were pregnant with their first child. Teenage mothers suffer particularly from severe complications during delivery, which result in higher morbidity and mortality for both the mother and her infant.

\subsubsection{Rationale for the Study}

Knowledge, perceptions and behavior related to reproductive health and sexual matters underlie virtually all the conditions that $\mathrm{FP} / \mathrm{MCH}$ programs address; hence these are important issues for FP researchers, population policy makers and service providers. To achieve significant levels of fertility or mortality declines, participation of adolescents in reproductive health programs including FP/MCH and PHC, is essential. Studies focusing on sexuality and attitude of adolescents on reproductive health, and the interacting influences of family, community and the social sector developmental programs (health, FP/MCH, education, women's development, etc.) would give useful revelations. The current study was designed to conduct in-depth research on adolescents' attitude, perceptions and behavior on sexuality and reproductive health in selected urban and rural settings.

Changes in the behavior of adolescents and their guardians in the family regarding reproductive health care and family life education can come about through planned interventions. Social mobilization would influence significant changes in the socio-cultural norms and beliefs held by the community leaders.

On the basis of such need, the current study was proposed to collect and analyze relevant data, comparing the adolescents of varied socio-cultural and programmatic backgrounds.

\subsection{OBJECTIVES}

The study was undertaken by Research Evaluation Associates For Development (READ) with support from the Population Council. The objectives of the study were to:

- Assess knowledge, attitudes and practices of the adolescents on reproductive health including FP-MCH and sexuality;

- Ascertain the level of understanding and behavior of the adolescents on reproductive health $(\mathrm{RH})$ including FP-MCH by social and spatial differences;

- Investigate socio-cultural values, beliefs and concerns related to sexuality and reproductive health of adolescents, husbands, guardians, service providers and the community leaders; and

- Explore the scope and medium for sex education for adolescents, its acceptability and non-acceptability by the family and community. 


\section{CHAPTER 2}

\section{Research Design and Methodologies}

\subsection{STUDY DESIGN}

The adolescents, males and females aged between 15-19, constituted the primary sample of the current study. The study universe included areas characterized by major geographical and of the current study. The study universe
socio-cultural factors: urban-rural classifications as well as regions (Divisions). The nature of
the study prompted sampling from a homogeneous social/geographical boundary allowing groups of adolescents (defined by age 15-19) and the sources of other influences (guardians and leaders) living within that geographical unit. The study was not to establish any national rates on adolescents' reproductive health behaviour; instead it attempted to explore the perceptive and behavioral (qualitative and not quantitative) aspects. For this reason, the sample did not have to be accurately nationally representative either in size or in distribution. However adequate samples representing socio-cultural and geographical diversities were taken.

Assuming that data on sexuality and reproductive health including FP-MCH practices would be difficult to collect from adolescents, the study adapted various approaches and data collection instruments. Comparisons of the findings from the different methods of data collection were made to ascertain the level of reliability and validity of the overall findings.

In order to obtain a comprehensive scenario related to sexuality and reproductive health including FP-MCH practices of the adolescents, data were collected from the adolescents and their guardians, community leaders and the service providers. A sub-sample of the guardians, community leaders and the service providers were taken from the same sample spots where the adolescents were interviewed. The study focused on adolescents and their pressure groups to ascertain the societal context (values, beliefs and norms) that surround them.

Within the same sample spot, urban or rural, respondents from both the poor and the well off sections were selected. In the rural areas, prior to actual interviews, enumeration was conducted to identify the adolescents and their economic background (poor or well off). Primarily housing structure, such as tin and brick roof represented well off section, while thatched house represented poor section. In the urban areas, interviews were conducted both in the urban slums, representing urban poor, and in the Housing Estates 'colonies' representing relatively well off sections of the society. The study sample in the urban areas included urban poor and middle class.

The Focus Group Discussions (FGDs) were conducted within the same sample spot, where the adolescents were interviewed, but separate samples for surveys and FGDs were covered. FGDs were conducted in the community, schools and in the health service centers.

\subsection{STUDY SAMPLE: AREAS AND SIZE}

The sample for the study was selected following a multi-stage stratified random sampling procedure. Irrespective of urban or rural locations, the thanas, unions, and the 12 
ultimate sampling spots, that is the mahallas (para/unit)/village, were selected randomly. The cities and the districts were selected purposively considering the factors of areal and sociocultural representativeness. Sample of the study included both rural and urban spots with a 33 percent urban and 66 percent rural distribution. Four cities were selected as urban spots: Dhaka, Chittagong, Khulna and Rajshahi; while 8 rural spots were selected from four other districts: Manikganj of Dhaka, Feni of Chittagong, Jessore of Khulna, and Rangpur of Rajshahi Division. From each city, one mahallah, and from each mahallah, one para/unit was selected, having a total of 4 paras/units as urban sample spots. Eight thanas, two from each of the four districts, one thana from accessible area (with metal road connection and with all types of facilities: health, education etc.) and the other from inaccessible areas (difficult communication linkage and relative absence of service facilities) were selected as rural sample. From each thana, one village, an accessible village from accessible thana, and inaccessible village from inaccessible thana, was selected, with a total of 8 villages as rural sample spots in the study. The sample size was estimated using the formula: $\left(Z^{2}=p q / d^{2}\right)$ with assumptions: $p=6$ percent awareness about STD, and $q=94$ percent being unaware with degree of accuracy estimated at .01 level, the total size of the sample was approximately 2,100 (Hossain, 1996).

\subsection{DATA COLLECTION AND INSTRUMENTS}

Data for the study were collected with multiple samples, administering different data collection approaches and techniques.

1. Interviews for the survey were conducted with standardized questionnaires for the adolescent sample of 1,261. Husbands (599) of the currently married female adolescents were interviewed with a comparable standardized questionnaire.

2. Fourteen FGDs were conducted with male and female selected adolescents separately in the institutions (schools/health centers) and out of institutions (community/slum/colony) with standard guidelines developed for the same. The FGDs were conducted to measure the degree of interaction and participation of the adolescents on selected topics of discussion: sexuality, STDs, RTI among others. Average time spent on each FGD was one and a half hours. Each FGD was conducted by a moderator with note taking by a trained personnel and a tape recorder. In the outset of the FGD sessions, personal history, such as bio-data and related family history were collected from each participant. On average each session had 7 participants.

3. Intensive interviews with guardians (94), community leaders (141) and Service Providers (98) were conducted with separate questionnaires designed and developed for the purpose.

4. In addition, 218 interviews were conducted by two teams consisting of experienced interviewers-cum-supervisors and doctors. The intensive interviews were conducted with the adolescent and husband sample. Twelve percent of respondents, earlier interviewed in the survey, were selected randomly from the sample spots. The purpose of the intensive interview was to assess the quality of adolescent survey interviews and also to find out whether intensive non-structured/non-standardized interviews would yield more in-depth, qualitative information on personal issues than were obtained through structured/standardized survey questionnaires. 
All the data collection instruments, questionnaires for survey interviews and the guidelines for FGD, were finalized after pretesting.

The study intensively investigated the degree of awareness, interactions and level of involvement of the adolescents (15-19 years) on human sexuality and reproductive health including FP/MCH and PHC measures. In addition, the study assessed the levels of influence of social organizations, family and the community including the influences of the guardians and the community leaders on the adolescents. Data was collected using seven different instruments:

i. Enumeration for identification of adolescents;

ii. Questionnaire for adolescents (15-19 years of age): males, females and their husbands;

iii. 'Guardians of male and female adolescents;

iv. Community leaders: males and females;

v. Service providers: males and females;

vi. FGD Guidelines for married and unmarried adolescents: males, females and their husbands; and

vii. Guidelines for quality control and intensive interviews of the adolescents including related medical investigations.

Data collection for the study commenced in September 1996 and continued until November 1996. In total 14 FGDs, 1,860 interviews with adolescents and husbands, 333 interviews with guardians, community leaders and the service providers were completed in 4 cities, 4 districts and 8 thanas of Bangladesh.

\subsection{CONSTRAINTS ENCOUNTERED DURING DATA COLLECTION}

1. Some guardians, especially the in-laws of female adolescents, posed obstructions during interviews. However convincing reasoning about anonymity, confidentiality and the overall importance of the survey regarding mothers health, helped resolve such problems.

2. Some young people who were observing the interviews, both in the urban and rural areas, created problems alleging that the interviews attempted to obtain socially prohibited information on sex. Such problems were resolved when the Field Supervisors involved the community leaders who supported the survey as an essential intervention for health development.

3. Married females of 15-19 years of age were difficult to locate in the urban colonies. As well, some of their husbands were outside the sample area.

4. The field interviewers, while collecting data in the cities, also had difficulty contacting the husbands of adolescent females, especially in the slums. Most of them were rickshaw pullers or were engaged in different labor intensive jobs which had no fixed working hours. The interviewers had to interview these respondents very early in the morning. 


\section{CHAPTER 3}

\section{Survey Design}

\subsection{FOCUS OF THE PAPER}

The foci of this report are three critical areas of reproductive health: family planning, MCH and sexuality. Policy and service program implications are highlighted. Critical variables are analyzed and interpreted by comparing findings from the different respondents, their location, and the type of data collection instrument used. The following major classifications of respondents are used throughout the report:

i. Female and male adolescents from the rural and urban areas: poor/slums and well off/colonies;

ii. Husbands of the female married adolescents from rural and urban areas: poor/slums and well off/colonies;

iii. Service providers, guardians and community leaders, males and females, from rural and urban areas: poor/slums and well off/colonies.

\subsection{SAMPLE AND DISTRIBUTION}

The study was conducted in four divisions, four cities, four other districts and in 12 thanas.

\begin{tabular}{|c|c|c|c|c|c|}
\hline \multirow[t]{2}{*}{ Division } & \multirow[t]{2}{*}{ Districts } & \multirow[t]{2}{*}{ Thanas } & \multicolumn{3}{|c|}{$\begin{array}{l}\text { Completed survey interviews, } \\
\text { FGDs, \& other }\end{array}$} \\
\hline & & & & $\mathbf{n} \mathbf{P}$ & Sample* \\
\hline Dhaka & $\begin{array}{l}\text { Dhaka } \\
\text { Manikganj }\end{array}$ & $\begin{array}{l}\text { Mirpur } \\
\text { Ghior } \\
\text { Singair }\end{array}$ & $\begin{array}{l}142 \\
155 \\
155 \\
\end{array}$ & $\begin{array}{l}2: 13^{* *} \\
1: 7 \\
2: 14\end{array}$ & $\begin{array}{l}16 \\
30 \\
30 \\
\end{array}$ \\
\hline Rajshahi & $\begin{array}{l}\text { Rajshahi } \\
\text { Rangpur }\end{array}$ & $\begin{array}{l}\text { Boalia } \\
\text { Mithapukur } \\
\text { Pirgacha }\end{array}$ & $\begin{array}{l}155 \\
156 \\
157 \\
\end{array}$ & $\begin{array}{l}1: 7 \\
1: 7 \\
1: 7\end{array}$ & $\begin{array}{l}25 \\
30 \\
30\end{array}$ \\
\hline Chittagong & $\begin{array}{l}\text { Chittagong } \\
\text { Feni }\end{array}$ & $\begin{array}{l}\text { Panchlaish } \\
\text { Chagalnaia } \\
\text { Porsuram }\end{array}$ & $\begin{array}{l}157 \\
158 \\
157 \\
\end{array}$ & $\begin{array}{l}1: 7 \\
1: 7 \\
1: 7 \\
\end{array}$ & $\begin{array}{l}26 \\
30 \\
30 \\
\end{array}$ \\
\hline Khulna & $\begin{array}{l}\text { Khulna } \\
\text { Jessore }\end{array}$ & $\begin{array}{l}\text { Khalishpur } \\
\text { Jhikargacha } \\
\text { Sarsa }\end{array}$ & $\begin{array}{l}156 \\
157 \\
155 \\
\end{array}$ & $\begin{array}{l}1: 6 \\
1: 7 \\
1: 7 \\
\end{array}$ & $\begin{array}{l}25 \\
30 \\
31 \\
\end{array}$ \\
\hline Total & 8 Districts & 12 thanas & 1860 & $14: 96$ & 333 \\
\hline
\end{tabular}

* Sub-Sample of Guardians, Community Leaders and Service Providers

**96 participants in 14 FGDs : $P$ (Participants), 6-7 participants in each FGD 


\subsubsection{Survey of the Adolescents and Husbands}

Of the total survey interviews $(1,860)$, about 33 percent were from urban locations, being equally divided between colonies and slums, while 67 percent were from rural areas, almost equally divided between 'well off' and 'poor' groups.

\section{Table 1}

Distribution of sample by areas and categories of respondents: for survey data collection with adolescents and husbands

\begin{tabular}{|c|c|c|c|c|c|}
\hline \multirow{3}{*}{$\begin{array}{l}\text { Categories } \\
\text { of } \\
\text { Respondents }\end{array}$} & \multicolumn{5}{|c|}{ Area } \\
\hline & \multicolumn{2}{|c|}{ Urban } & \multicolumn{2}{|c|}{ Rural } & \multirow{2}{*}{$\begin{array}{l}\text { Row } \\
\text { Total }\end{array}$} \\
\hline & Colony & Slum & Well off & Poor & \\
\hline Female unmarried & 58 & 57 & 123 & 101 & $\begin{array}{c}339 \\
18.2 \% \\
\end{array}$ \\
\hline Female married & 103 & 104 & 209 & 207 & $\begin{array}{c}623 \\
33.5 \% \\
\end{array}$ \\
\hline Male unmarried & 53 & 48 & 99 & 99 & $\begin{array}{c}299 \\
16.1 \% \\
\end{array}$ \\
\hline Husbands & 88 & 100 & 207 & 204 & $\begin{array}{c}599 \\
32.2 \%\end{array}$ \\
\hline $\begin{array}{l}\text { Column } \\
\text { Total }\end{array}$ & $\begin{array}{c}302 \\
16.2 \%\end{array}$ & $\begin{array}{c}309 \\
16.6 \%\end{array}$ & $\begin{array}{c}638 \\
34.3 \%\end{array}$ & $\begin{array}{c}611 \\
32.8 \%\end{array}$ & $\begin{array}{c}1860 \\
100.0 \%\end{array}$ \\
\hline
\end{tabular}

Two-thirds of the survey sample were female married adolescents (33.5 percent) and their husbands ( 32.2 percent), while the rest were male (16.1 percent) and female (18.2 percent) unmarried adolescents.

\subsubsection{FGDs with Adolescents and Husbands}

In total, 14 FGDs were conducted with rural (9) and urban (5) adolescents (11) and their husbands (3). Half of these were with females and half with males. On average each FGD had 7 participants, giving a total of 96 FGD participants which could be broken down in the following manner: 
Table 2

Distribution of FGD sample by respondents and geographical classifications

\begin{tabular}{|l|c|c|c|c|c|}
\hline \multirow{2}{*}{ Categories } & \multirow{2}{*}{ Total } & \multicolumn{3}{|c|}{ A d o l e s c e n t s } & \multirow{3}{*}{ H } \\
\cline { 2 - 5 } & & \multicolumn{2}{|c|}{ F e m a . } & M a l e & Husbands \\
\cline { 2 - 5 } & $\mathbf{n}$ & Unmarried & Married & Unmarried & \\
\hline A. Rural: & $\mathbf{6 3}$ & $\mathbf{1 4}$ & $\mathbf{2 1}$ & $\mathbf{1 4}$ & $\mathbf{1 4}$ \\
1. Community: & 21 & 0 & 14 & 0 & 7 \\
$\quad$ Poor & 7 & 0 & 7 & 0 & 0 \\
Well-off & 14 & 0 & 7 & 0 & 7 \\
2. School: & 28 & 14 & 0 & 14 & 0 \\
3. Health & 14 & 0 & 7 & 0 & 7 \\
Center: & & & & & \\
Total (1.2.3) & $\mathbf{6 3}$ & $\mathbf{1 4}$ & $\mathbf{2 1}$ & $\mathbf{1 4}$ & $\mathbf{1 4}$ \\
\hline B. Urban: & $\mathbf{3 3}$ & 7 & 6 & 14 & 6 \\
1. Community & 19 & 0 & 6 & 7 & 6 \\
Poor & 13 & 0 & 6 & 7 & 0 \\
Well-off & 6 & 0 & 0 & 0 & 6 \\
2. School & 14 & 7 & 0 & 7 & 0 \\
3. Health & 0 & 0 & 0 & 0 & 0 \\
Center: & & & & & \\
Total (1.2.3) & $\mathbf{3 3}$ & $\mathbf{7}$ & $\mathbf{6}$ & $\mathbf{1 4}$ & $\mathbf{6}$ \\
\hline All Total & $\mathbf{9 6}$ & $\mathbf{2 1}$ & $\mathbf{2 7}$ & $\mathbf{2 8}$ & $\mathbf{2 0}$ \\
\hline
\end{tabular}

About one-third of the FGD respondents were from the urban, and the rest from rural areas. The respondents by gender were almost equally divided into married and unmarried groups. About one-fifth of the total respondents were the husbands of the adolescent females (married), and four-fifths adolescents. Of the adolescents (76), one-third were married and twothirds unmarried.

\subsubsection{Guardians, Service Providers and Community Leaders}

Under this category, a total of 333 respondents were interviewed. The classifications were: guardians (94), community leaders (141), and service providers (98). The service providers consisted of FWV: 19, FWAs: 32, HAs: 41, and NGO FWs: 6. The distribution of the respondents by geographical and gender classifications is shown in Table 3 :

\section{Table 3}

Distribution of the guardians, community leaders and the service providers

\begin{tabular}{|l|c|c|c|c|c|r|r|}
\hline \multirow{2}{*}{$\begin{array}{l}\text { Categories of } \\
\text { Respondents }\end{array}$} & \multicolumn{2}{|c|}{ Urban } & \multicolumn{2}{c|}{ Rural } & \multicolumn{2}{c|}{ Total } & \multirow{2}{*}{ All } \\
\cline { 2 - 7 } & Female & Male & Female & Male & Female & Male & \\
\hline Guardians & 16 & 14 & 32 & 32 & 48 & 46 & 94 \\
Community Leaders & 17 & 28 & 36 & 60 & 53 & 88 & 141 \\
Service Providers & 16 & 1 & 46 & 35 & 62 & 36 & 98 \\
Total & 49 & 43 & 114 & 127 & 163 & 170 & 333 \\
\hline
\end{tabular}


Table 2

Distribution of FGD sample by respondents and geographical classifications

\begin{tabular}{|l|c|c|c|c|c|}
\multirow{2}{*}{ Categories } & \multirow{2}{*}{ Total } & \multicolumn{2}{|c|}{ A d o l e s c e n t s } & \multirow{2}{*}{ Husbands } \\
\cline { 2 - 5 } & & \multicolumn{2}{|c|}{ F e m a l e } & M a l e & \\
\cline { 2 - 5 } & $\mathbf{n}$ & Unmarried & Married & Unmarried & \\
\hline A. Rural: & $\mathbf{6 3}$ & $\mathbf{1 4}$ & $\mathbf{2 1}$ & $\mathbf{1 4}$ & $\mathbf{1 4}$ \\
1. Community: & 21 & 0 & 14 & 0 & 7 \\
$\quad$ Poor & 7 & 0 & 7 & 0 & 0 \\
Well-off & 14 & 0 & 7 & 0 & 7 \\
2. School: & 28 & 14 & 0 & 14 & 0 \\
3. Health & 14 & 0 & 7 & 0 & 7 \\
Center: & & & & & \\
Total (1.2.3) & $\mathbf{6 3}$ & $\mathbf{1 4}$ & $\mathbf{2 1}$ & $\mathbf{1 4}$ & $\mathbf{1 4}$ \\
\hline B. Urban: & $\mathbf{3 3}$ & 7 & 6 & 7 & 6 \\
1. Community & 19 & 0 & 6 & 7 & 0 \\
Poor & 13 & 0 & 6 & 0 & 6 \\
Well-off & 6 & 0 & 0 & 7 & 0 \\
2. School & 14 & 7 & 0 & 0 & 0 \\
3. Health & 0 & 0 & 0 & $\mathbf{1 4}$ & $\mathbf{6}$ \\
Center: & & & $\mathbf{6}$ & $\mathbf{2 8}$ & $\mathbf{2 0}$ \\
Total (1.2.3) & $\mathbf{3 3}$ & $\mathbf{7}$ & $\mathbf{2 1}$ & $\mathbf{2 7}$ & \\
\hline All Total & $\mathbf{9 6}$ & & &
\end{tabular}

About one-third of the FGD respondents were from the urban, and the rest from rural areas. The respondents by gender were almost equally divided into married and unmarried groups. About one-fifth of the total respondents were the husbands of the adolescent females (married), and four-fifths adolescents. Of the adolescents (76), one-third were married and twothirds unmarried.

\subsubsection{Guardians, Service Providers and Community Leaders}

Under this category, a total of 333 respondents were interviewed. The classifications were: guardians (94), community leaders (141), and service providers (98). The service providers consisted of FWV: 19, FWAs: 32, HAs: 41, and NGO FWs: 6 . The distribution of the respondents by geographical and gender classifications is shown in Table 3 :

\section{Table 3}

Distribution of the guardians, community leaders and the service providers

\begin{tabular}{|l|c|c|c|c|c|r|r|}
\hline \multirow{2}{*}{ Categories of } & \multicolumn{2}{|c|}{ Urban } & \multicolumn{2}{c|}{ Rural } & \multicolumn{2}{c|}{ Total } & \multirow{2}{*}{ All } \\
\cline { 2 - 8 } Respondents & Female & Male & Female & Male & Female & Male & \\
\hline Guardians & 16 & 14 & 32 & 32 & 48 & 46 & 94 \\
Community Leaders & 17 & 28 & 36 & 60 & 53 & 88 & 141 \\
Service Providers & 16 & 1 & 46 & 35 & 62 & 36 & 98 \\
Total & 49 & 43 & 114 & 127 & 163 & 170 & 333 \\
\hline
\end{tabular}


Of the total respondents, guardians constituted 28 percent (male: 49 percent and female: 51 percent), community leaders 42 percent (male: 62 percent and female 38 percent) and the service providers 30 percent (male: 37 percent and female: 63 percent).

\section{$\underline{\text { 3.2.4 Intensive Interviews }}$}

In total, 218 intensive interviews were conducted and 100 percent of the respondents stated that they were earlier interviewed in the survey phase of the study. The distribution of the respondents is in Table 4:

\section{Table 4}

\section{Distribution of the intensive (qualitative) interviews}

\begin{tabular}{|l|c|c|c|c|c|}
\hline \multirow{2}{*}{$\begin{array}{l}\text { Categories of } \\
\text { Respondents }\end{array}$} & \multicolumn{2}{|c|}{ Urban } & \multicolumn{2}{c|}{ Rural } & Total \\
\cline { 2 - 5 } & Colonies & Slums & Well off & Poor & \\
\hline $\begin{array}{l}\text { Married female } \\
\text { adolescents }\end{array}$ & 14 & 17 & 12 & 15 & 58 \\
$\begin{array}{l}\text { Unmarried female } \\
\text { adolescents }\end{array}$ & 15 & 13 & 13 & 14 & 55 \\
$\begin{array}{l}\text { Unmarried males } \\
\text { adolescents }\end{array}$ & 15 & 10 & 11 & 12 & 48 \\
Husbands & 10 & 17 & 13 & 17 & 57 \\
\hline Total & 54 & 57 & 49 & 58 & 218 \\
\hline
\end{tabular}

Thirteen percent of the adolescent sample (females and males) were followed-up through intensive interviews, where simple guidelines were used instead of a structured questionnaire. Similarly, 10 percent of the husbands were also interviewed following the same methodology. 


\section{CHAPTER 4}

\section{Findings And Discussions}

\subsection{SOCIO ECONOMIC AND DEMOGRAPHIC CHARACTERISTICS}

\subsubsection{Survey Respondents}

The mean age of the female and male adolescents was comparable; it ranged between 16 and 18 years, while the mean ages of the husbands were 25 years and 27 years respectively, for the slum/poor and colony/well off backgrounds. The overwhelming majority of the unmarried adolescents living in the urban colonies (98 percent females and 91 percent males) had completed education up to grade six and above, while only one-third ( 33 percent) of the unmarried adolescents in the slum, males or females, had completed a comparable level of education. Again an overwhelming majority of the rural unmarried adolescent males (88 percent) and females ( 90 percent), of well off backgrounds, reported completing education at grade six or above. The rural poor compared to the urban poor in the slums, reported completion of higher levels of education - 60 percent of the rural poor had completed education at grade six and above. The level of education of the married adolescents was uniformly lower than their unmarried counterparts of varying backgrounds. Current statistics (BBS 1995) show a sharp rise in the attendance of girls and boys in the schools. The adult literacy rates (age 15+) cited by BBS study in 1995 for males in the urban areas was 71.2 percent, while for the females it was 53 percent. Women's representation at the higher secondary level and above was increasing steadily (Hossain, 1996).

Participation in income-generating occupations was low for the rural female adolescents of poor background ( 9 percent), while a much larger proportion of their male counterparts ( 46 percent) reported to be engaged in income earning occupations. One-fifth (23 percent) of the female unmarried adolescents residing in slums reported to be participating in income earning occupations, compared to a much larger proportion of their male counterparts ( 75 percent). Participation in income earning occupations by the married female adolescents was the least, irrespective of socio-economic status or place of residence.

Although estimates of family income obtained through formal interviews may not be that accurate, interesting features, by mean monthly family income levels of the adolescents of varying socio-economic backgrounds, were observed. The highest incomes were reported by the rural well off group; their mean monthly family income somewhat exceeding that of those living in the colonies. The income levels of the adolescents' families in the slum and of the rural poor were comparable.

\subsubsection{FGD Respondents}

In the rural areas, a little less than half ( 45 percent) of the participants were from the schools, one-third from the community ( 33 percent out of school), and about one-fifth (22 percent) from the health centers. In the urban areas more than half were from the community (58 percent), and the rest from schools ( 42 percent). 
All the adolescents, irrespective of their marital status or geographical location, were selected within the age range 15 to 19 years, while the husbands of the adolescents were within the age range 19 to 36 years. Most of the adolescents, by occupation, were either housewives or students, with the exception of one group of unmarried males of poor background in the urban area, who were either laborers or shopkeepers. Most of the husbands claimed to be shopkeepers, business men, farmers or laborers, and a few were unemployed.

\subsubsection{Special Groups: Guardians, Community Leaders and Service Providers}

\subsection{3a Guardians}

Three-fourths of the guardians were parents, of whom 42 percent were fathers and 33 percent mothers of adolescents. A little over a quarter were male in-laws (4 percent) and female in-laws (18 percent). The rest were uncles and grandfathers/mothers. The mean ages of the parents and the in-laws were comparable (52 years). More than two-thirds (69 percent) of the guardians had completed primary education or less, 20 percent completed education above sixth grade, and about ten percent had education at SSC or higher levels. A little less than half (44 percent) of the guardians were housewives only, one-fifth in business (20 percent) or farming ( 21 percent), 10 percent were service holders and the rest ( 5 percent) were unemployed. The mean monthly family income reported by the guardians was as follows:

\begin{tabular}{|l|c|}
\hline Family in the colony & Tk. 3660.00 \\
Family in the slum & Tk. 1613.00 \\
Family in the rural well off areas & Tk. 4311.00 \\
Family in the rural poor areas & Tk. 1308.00 \\
\hline
\end{tabular}

The mean number of living children per family was 5.44 and there was a marginal difference in parity by categories of respondents:

\begin{tabular}{|l|l|}
\hline Colony & 5.6 children \\
Slum & 5.3 children \\
Well off & 5.8 children \\
Poor & 5.0 children \\
\hline
\end{tabular}

\subsection{3b Community Leaders}

Three-fourths of the leaders in the urban colonies, about two-thirds (62 percent) from the well off groups (rural leaders), half of those in the slums and only a quarter of the rural poor, had completed education equivalent to grade 12 or above. A little less than two-thirds of the community leaders (61 percent) from urban colonies reported a monthly income of Tk. 4000.00 and above, while 49 percent of the well off group reported the same level of income. In contrast, the majority of the community leaders from the slum (68 percent) and from the 
poor (92 percent) in the rural areas, reported a monthly income of less than Tk 4000 . It is likely that the monthly income was to some extent underestimated.

\subsection{3c Service Providers}

The average age of the service providers was 38 years with marginal differences between the categories of personnel namely, FWVs, FWAs, FWs/NGO, and HAs. The HAs and the FWVs reported to have completed education at SSC level or above, while the majority of the FWAs/FWs ( $>80$ percent) reported completed education upto secondary level. The service providers reported a mean number of living children of 2.5 , with little difference between the cadres.

\subsection{MEDIA EXPOSURE}

The adolescents reported television as the most popular medium of mass communication, followed by radio. Table 5 shows the distribution of the adolescents including husbands, by their status of exposure to mass media on a regular basis:

Table 5

\% Distribution of the adolescents and husbands by exposure to mass media on a regular basis

\begin{tabular}{|l|c|c|c|c|c|c|c|c|}
\hline \multirow{2}{*}{$\begin{array}{l}\text { Categories of } \\
\text { Respondents }\end{array}$} & \multicolumn{2}{c|}{$\begin{array}{c}\text { Colonies } \\
\text { (\%) }\end{array}$} & \multicolumn{2}{c|}{$\begin{array}{c}\text { Well Off } \\
\text { (\%) }\end{array}$} & \multicolumn{2}{c|}{$\begin{array}{c}\text { Slums } \\
\text { (\%) }\end{array}$} & \multicolumn{2}{c|}{$\begin{array}{c}\text { Poor } \\
\text { (\%) }\end{array}$} \\
\cline { 2 - 10 } & TV & Radio & TV & Radio & TV & Radio & TV & Radio \\
\hline Female Unmarried & 81 & 22 & 74 & 33 & 44 & 12 & 44 & 21 \\
Female Married & 68 & 20 & 54 & 28 & 17 & 14 & 20 & 17 \\
Male Unmarried & 64 & 28 & 60 & 37 & 23 & 17 & 34 & 29 \\
Husbands & 42 & 18 & 42 & 45 & 20 & 16 & 25 & 23 \\
\hline
\end{tabular}

The unmarried female adolescents, residing either in urban colonies or in the well off sections of rural areas, were predominantly attracted to television. Nearly two-thirds of them regularly viewed television, while a little less than half (44 percent) of their counterparts in the slums and in the poor sections of the rural areas reported to be viewing television regularly. The exposure of the married females to regular viewing of television in the colonies was 68 percent, followed by those in the rural areas of well off backgrounds ( 54 percent). For the poor in the rural areas, it was 20 percent and for urban slum residents, it was only 17 percent. The exposure of the unmarried males to regular television viewing was 64 percent in the colonies, 60 percent in the rural areas among the well off group, 34 percent among the poor in the rural areas, and only 23 percent among the slum dwellers. The exposure of the adolescents to radio on a regular basis was one-third of that of television. From here it is evident that television is a powerful medium for targeting the adolescents both in the urban and the rural areas. 


\subsection{SEXUALITY}

\subsubsection{Sexual Experience Outside Marriage}

The survey revealed that knowledge about the sex act (jono kria) was held by the majority of adolescents, although 12 per cent of unmarried adolescent females and 7 per cent of unmarried adolescent males said they did not have any knowledge. There is no substantial publicity on the subject of sex either through media or through formal institutuions in Bangladesh. Restrictions on open discussion of the topic of sexual intercourse are prevalent in the society. Reported lack of knowledge was much higher in urban areas than rural areas, as high as 25 per cent of unmarried girls and 23 per cent of unmarried males in slum areas. Adolescents in rural areas are more likely to be exposed to information about sexual intercourse because of closer social and living arrangements, including unmarried boys and girls sharing rooms with married people. Since the proportion for unmarried males in slum areas is absolutely higher than the corresponding proportion without experience of premarital sexual intercourse, it seems likely that claims of lack of knowledge should be discounted in many cases.

Respondents were asked several questions which enable an assessment of the occurrence of premarital experience of sexual intercourse. Firstly, married adolescent women and their husbands were asked directly if they had experienced premarital intercourse. Secondly, all respondents, including unmarried adolescents, were asked the age at which they first experienced sexual intercourse. In the case of unmarried adolescents, positive responses to the second question could be used to assess if they had ever had intercourse. In the case of married adolescents, the answer to the second question could be compared with their ages at marriage; where age at first intercourse was calculated to be lower than age at marriage, premarital sexual experience could be assumed.

The combination of these responses produced a considerably higher proportion with premarital experience than the more direct question, especially in the case of adolescent females. Table 6 compares the premarital sex experience of respondents, as determined by the combined measure. Since there were no major differences between 'colony' and 'slum' urban areas, or between 'well-off' and 'poor' rural areas, these categories have been combined for the purposes of the table. 
Table 6

Experience of Premarital Sexual Intercourse, by Marital Status, Age and Rural or Urban Residence

\begin{tabular}{|c|c|c|c|c|c|}
\hline \multirow{2}{*}{$\begin{array}{l}\text { Marital } \\
\text { status \& } \\
\text { rural/urban } \\
\text { residence } \\
\end{array}$} & \multicolumn{5}{|c|}{ Age (unmarried) or age at marriage } \\
\hline & $<16$ & 16 & 17 & 18 & $19+$ \\
\hline \multicolumn{6}{|c|}{$\begin{array}{l}\text { residence } \\
\text { Unmarried females: }\end{array}$} \\
\hline Urban & $14 \%$ & $13 \%$ & $20 \%$ & $35 \%$ & $47 \%$ \\
\hline Rural & $3 \%$ & $7 \%$ & $7 \%$ & $6 \%$ & $5 \%$ \\
\hline Total & $6 \%$ & $9 \%$ & $10 \%$ & $18 \%$ & $24 \%$ \\
\hline $\mathrm{N}$ & 116 & 90 & 40 & 56 & 37 \\
\hline \multicolumn{6}{|c|}{$\frac{\mathrm{N}}{\text { Married females: }}$} \\
\hline Urban & $10 \%$ & $28 \%$ & $24 \%$ & $25 \%$ & $40 \%$ \\
\hline Rural & $6 \%$ & $7 \%$ & - & $5 \%$ & - \\
\hline Total & $8 \%$ & $13 \%$ & $9 \%$ & $12 \%$ & $29 \%$ \\
\hline $\mathrm{N}$ & 389 & 136 & 54 & 34 & 7 \\
\hline \multicolumn{6}{|c|}{\begin{tabular}{c|c}
$\mathrm{N}$ & 389 \\
Unmarried males:
\end{tabular}} \\
\hline Urban & $64 \%$ & $80 \%$ & $67 \%$ & $88 \%$ & $88 \%$ \\
\hline Rural & $4 \%$ & $26 \%$ & $25 \%$ & $38 \%$ & $44 \%$ \\
\hline Total & $31 \%$ & $40 \%$ & $36 \%$ & $54 \%$ & $61 \%$ \\
\hline $\mathrm{N}$ & 48 & 58 & 55 & 72 & 66 \\
\hline \multicolumn{6}{|l|}{ Husbands: } \\
\hline Urban & $100 \%$ & $67 \%$ & $83 \%$ & $91 \%$ & $93 \%$ \\
\hline Rural & - & $40 \%$ & $33 \%$ & $61 \%$ & $58 \%$ \\
\hline Total & $33 \%$ & $46 \%$ & $58 \%$ & $69 \%$ & $69 \%$ \\
\hline $\mathrm{N}$ & 3 & 13 & 12 & 39 & 527 \\
\hline
\end{tabular}

With the exception of married and unmarried adolescent women in rural areas, all categories of respondents had increasing prevalence of premarital sexual intercourse with increasing age or age at marriage. Note that the majority of urban males had already experienced premarital sexual intercourse at all of the ages shown in the table, and large minorities of urban women, whether married or unmarried, had already experienced sexual intercourse by their late teens if they had not yet married. Premarital sexual intercourse seems to begin later for men in rural areas, and is at a very low level for women in rural areas. Because of very different age distributions for the different categories, it is not possible to make meaningful comparisons between mean ages at first intercourse. However, it is possible to compare the mean differences in reported age at marriage and first intercourse. The mean difference was zero years for women from all types of geographical location, but for men it was 8 years for colony (urban housing estate) areas, 6 years for urban slums, 4 years for well-off rural areas and 3 years for poor rural areas.

The composite measure of prevalence of premarital sexual experience used here produced higher proportions of males, both unmarried and married, who had had sex before marriage than were found from intensive interviews. In intensive interviews, 27 per 
cent of unmarried adolescent males admitted experience of intercourse (compared with 46 per cent who stated an age of first intercourse), while 51 per cent of husbands admitted premarital experience (compared with 68 per cent by the composite measure).

Very few women, married or unmarried, admitted premarital experience in intensive interviews. Moreover, while substantial minorities of married adolescent women in both urban and rural areas had prior relationship or contact with their future husbands (colony 28 per cent, slum 25 per cent, rural well-off 16 per cent, rural poor 10 per cent) or with other men ( 2 to 6 per cent), this contact was overwhelmingly described as only 'mental intimacy' or social and romantic interactions ( 94 per cent of respondents who had any contact), with only 3 per cent admitting any kind of physical intimacy. These findings are supported in another way by the answers given by husbands to a question on whether they had a sexual relationship with their wives after the marriage was negotiated and before the marriage itself - fewer than 2 per cent said they did.

Husbands of adolescent women were asked if they had had extramarital sexual experience. With increasing duration of marriage, there is a significant increase in the proportion who acknowledged having had intercourse outside marriage, as shown in Table 7.

\section{Table 7}

Extramarital Sexual Experience of Husbands of Adolescent Women, by Duration of Marriage and Location

\begin{tabular}{|l|c|c|c|c|c|c|}
\hline $\begin{array}{l}\text { Duration of } \\
\text { Marriage }\end{array}$ & Colony & Slum & $\begin{array}{l}\text { Rural } \\
\text { well-off }\end{array}$ & $\begin{array}{l}\text { Rural } \\
\text { Poor }\end{array}$ & Total & N \\
\hline $\begin{array}{l}\text { Less than } 2 \\
\text { years }\end{array}$ & $4 \%$ & $4 \%$ & $17 \%$ & $16 \%$ & $14 \%$ & 199 \\
\hline $2-4$ years & $5 \%$ & $13 \%$ & $25 \%$ & $24 \%$ & $19 \%$ & 241 \\
\hline $\begin{array}{l}5 \text { or more } \\
\text { years }\end{array}$ & $17 \%$ & $28 \%$ & $23 \%$ & $25 \%$ & $24 \%$ & 148 \\
\hline Total (a) & $7 \%$ & $14 \%$ & $21 \%$ & $22 \%$ & $18 \%$ & 589 \\
\hline
\end{tabular}

(a) Includes 21 cases with missing information for duration of marriage

In urban areas, whether colony or slum, respondents were less likely to acknowledge extramarital sexual experience if they had been married for shorter durations, but for all types of location at least one in six men married five or more years acknowledged extramarital experience. Of those who had sex with partners outside of marriage, 71 per cent mentioned commercial sex workers, 40 per cent mentioned girlfriends and 15 per cent mentioned other partners. Intensive interviews revealed a much higher level of extramarital experience by men, 28 per cent compared with 18 per cent in Table 7. As in the case of premarital sexual experience, very few women admitted extramarital experience.

The female participants in focus group discussions did not refer to their personal experiences when discussing extra-marital or pre-marital sex. Instead, they referred to the 
experience of their friends and relatives. In the focus group discussions for adolescent males, there were unmarried participants from rural areas and urban slums who referred to their own experience of pre-marital sex. Male participants from well-off areas, whether rural or urban colony, referred to both pre-marital and extra-marital sexual experience that they had.

While there should be some uncertainty about the level of both premarital and extramarital experience as admitted in various ways by respondents, the patterns shown in Tables 6 and 7 reveal important differences which have implications for reproductive health programs among adolescents. The most outstanding feature of these patterns is the existence of substantial levels of premarital or extramarital experience by males, compared with very low levels of premarital experience reported by women. There is no inconsistency in this. The women marry at very young ages compared with their husbands, and if they do not marry by their late teens they are much more likely to have already had sex with a man. For men, the most common type of partner for extramarital sex is a commercial sex worker. These behavioral patterns are common to both well-off and poor, but there are geographical differences, with premarital sex being at higher intensity in urban areas and extramarital sex at higher intensity in rural areas.

\subsubsection{Experience of puberty}

The onset of puberty is marked by first menstruation (menarche) for adolescent females and by occurrence of nocturnal emission or masturbation for adolescent males.

The average age at first menstruation reported by the female adolescents was 13 years irrespective of their marital or residential characteristics, and there was little variation from the average, with 94 per cent of female respondents reporting 12,13 or 14 as the age at which it occurred. Among married respondents, 5 per cent reported an age at menarche higher than their age of marriage and 14 per cent reported the same age for both events, leaving 82 per cent who had definitely experienced menstruation before their marriage. Table 8 shows the distribution of prior knowledge about menstruation among adolescent women, and the first sources of their information if they had any prior knowledge: 


\section{Table 8}

Adolescent Women and Prior Knowledge about Menstruation, by Marital Status, Source of Information and Location

\begin{tabular}{|l|c|c|c|c|c|}
\hline \multirow{2}{*}{} & \multicolumn{2}{|c|}{ Urban } & \multicolumn{2}{c|}{ Rural } & \multirow{2}{*}{ Total } \\
\cline { 2 - 4 } & Colony & Slum & Well-off & Poor & \\
\hline \multicolumn{5}{|l|}{ Marital status (proportion with prior knowledge) } \\
\hline Unmarried & $52 \%$ & $58 \%$ & $59 \%$ & $70 \%$ & $61 \%$ \\
\hline Married & $64 \%$ & $63 \%$ & $64 \%$ & $64 \%$ & $64 \%$ \\
\hline First source of information (percentage distribution): \\
\hline Mother & $12 \%$ & $6 \%$ & $7 \%$ & $4 \%$ & $7 \%$ \\
\hline Sister & $25 \%$ & $12 \%$ & $23 \%$ & $12 \%$ & $18 \%$ \\
\hline Sister-in-law & $25 \%$ & $27 \%$ & $24 \%$ & $34 \%$ & $28 \%$ \\
\hline Friend & $28 \%$ & $33 \%$ & $37 \%$ & $34 \%$ & $34 \%$ \\
\hline Neighbor & $5 \%$ & $10 \%$ & $2 \%$ & $4 \%$ & $5 \%$ \\
\hline Other & $6 \%$ & $11 \%$ & $7 \%$ & $11 \%$ & $9 \%$ \\
\hline $\begin{array}{l}\text { Number with } \\
\text { prior } \\
\text { knowledge }\end{array}$ & 98 & 99 & 206 & 203 & 606 \\
\hline
\end{tabular}

There was no variation between geographical areas in the proportion of married adolescents who had information about menstruation before they experienced it, and the slight variation among unmarried respondents is mainly due to some sensitivity about the subject among unmarried urban residents. On the other hand, the sources of first information differ markedly between well-off and poor areas. In all areas, about one in three respondents had obtained their first information from friends, but in urban colonies and well-off rural areas they were much more likely to have obtained information from their mothers or sisters than were women from urban slums or poor rural areas. Respondents from the less well-off areas were also slightly more likely to have obtained information from sisters-in-law, and considerably more likely to have obtained their information from more distant sources, such as neighbors.

With such large proportions of girls experiencing menstruation before they had any knowledge about it, it would hardly be surprising if for many it was a traumatic experience. Reactions of shock, surprise and fright were indeed reported by the overwhelming majority of respondents (84 per cent), but there was no significant difference in incidence between the women who said they had prior knowledge about menstruation and those who said they did not, and reports of extreme shock were reported by a much smaller proportion of women, a little over 10 per cent. This lack of difference might indicate that the 'prior knowledge' possessed by many respondents was not extensive. 
Among male respondents, the mean age at which nocturnal emission or masturbation was first experienced was 14.6 years, but this was considerably more variable than age of first menstruation among female respondents. Just under half (49 per cent) of male respondents said that they had masturbated, at least once. The overwhelming majority of male respondents ( 91 per cent) said that they had first heard about night emission from a friend, rather than from a relative, neighbor or other source.

Findings from focus group discussions closely matched those obtained from survey respondents, whether male or female, regarding their first experiences of menstruation or nocturnal emission, their reactions to the event and their sources of information.

\subsubsection{Sex Education}

In a society where marriage takes place soon after puberty for many adolescent women, their knowledge about sexual relationships is often limited. Among married adolescents, 41 per cent (ranging from 30 per cent in well-off rural areas to 61 per cent in urban slums) said they had no knowledge of sex before they had intercourse with their husbands.

Respondents were not asked whether sex education should be given, but were asked at which age sex education should be given. The most common response from males was to nominate the age range 16-19; overall, this response was given by 40 per cent of male respondents, but in colony and urban slum areas considerably higher proportions nominated lower age ranges (49 per cent and 47 per cent respectively). In the case of female respondents, the most common response was to nominate the age range 13-15, with 44 per cent giving this response, and a further 17 per cent nominated younger ages. The age range 13-15 corresponds with the ages at which menstruation begins for most young women, and the pattern of response indicates that a majority of respondents think that sex education should be given to adolescent women either before menarche or coinciding with it.

When respondents were asked which media or persons were appropriate for sex education, the pattern of response was completely different for female and male respondents. Female adolescents nominated grandmothers as the most appropriate source most commonly (44 per cent of female respondents), followed by female friends (39 per cent) and elder sisters (23 per cent). Male respondents showed an overwhelming preference for media sources, with 76 per cent mentioning radio and 73 per cent mentioning television, followed by newspapers and magazines (33 per cent) and books (30 per cent). By contrast, only 14 per cent of women nominated radio and 12 per cent nominated television as appropriate, and the most popular medium was books (16 per cent). However, there are differences between unmarried and married women, as Table 9 shows. 
Table 9

Distribution (\%) of Appropriate Sources for Sex Education

\begin{tabular}{|c|c|c|c|c|c|}
\hline & Colony & Slum & Well-off & Poor & Total \\
\hline \multicolumn{6}{|l|}{ Unmarried females: } \\
\hline Newspaper/magazine & $36 \%$ & $18 \%$ & $25 \%$ & $8 \%$ & $21 \%$ \\
\hline Radio & $21 \%$ & $19 \%$ & $29 \%$ & $10 \%$ & $20 \%$ \\
\hline Television & $24 \%$ & $12 \%$ & $25 \%$ & $9 \%$ & $18 \%$ \\
\hline Books & $26 \%$ & $25 \%$ & $29 \%$ & $17 \%$ & $24 \%$ \\
\hline School & $12 \%$ & $4 \%$ & $13 \%$ & $10 \%$ & $10 \%$ \\
\hline Female friend & $33 \%$ & $56 \%$ & $37 \%$ & $48 \%$ & $43 \%$ \\
\hline Elder sister & $14 \%$ & $12 \%$ & $18 \%$ & $18 \%$ & $16 \%$ \\
\hline Grandmother & $14 \%$ & $42 \%$ & $28 \%$ & $52 \%$ & $35 \%$ \\
\hline Any other relative & $24 \%$ & $14 \%$ & $23 \%$ & $24 \%$ & $22 \%$ \\
\hline Any other source & $34 \%$ & $28 \%$ & $50 \%$ & $62 \%$ & $47 \%$ \\
\hline $\mathrm{N}$ & 58 & 57 & 123 & 101 & 339 \\
\hline \multicolumn{6}{|l|}{ Married females: } \\
\hline Newspaper/magazine & $18 \%$ & $7 \%$ & $9 \%$ & $2 \%$ & $8 \%$ \\
\hline Radio & $17 \%$ & $13 \%$ & $11 \%$ & $4 \%$ & $10 \%$ \\
\hline Television & $20 \%$ & $10 \%$ & $10 \%$ & $1 \%$ & $9 \%$ \\
\hline Books & $18 \%$ & $2 \%$ & $19 \%$ & $3 \%$ & $14 \%$ \\
\hline School & $3 \%$ & $0 \%$ & $7 \%$ & $1 \%$ & $3 \%$ \\
\hline Female friend & $32 \%$ & $30 \%$ & $37 \%$ & $41 \%$ & $37 \%$ \\
\hline Elder sister & $19 \%$ & $29 \%$ & $30 \%$ & $26 \%$ & $27 \%$ \\
\hline Grandmother & $31 \%$ & $51 \%$ & $53 \%$ & $54 \%$ & $49 \%$ \\
\hline Any other relative & $30 \%$ & $31 \%$ & $36 \%$ & $33 \%$ & $33 \%$ \\
\hline Any other source & $41 \%$ & $34 \%$ & $56 \%$ & $60 \%$ & $51 \%$ \\
\hline $\mathrm{N}$ & 103 & 103 & 209 & 206 & 621 \\
\hline \multicolumn{6}{|l|}{ Unmarried males: } \\
\hline Newspaper/magazine & $49 \%$ & $21 \%$ & $44 \%$ & $33 \%$ & $38 \%$ \\
\hline Radio & $68 \%$ & $42 \%$ & $84 \%$ & $83 \%$ & $74 \%$ \\
\hline Television & $60 \%$ & $33 \%$ & $80 \%$ & $76 \%$ & $68 \%$ \\
\hline Books & $64 \%$ & $33 \%$ & $36 \%$ & $27 \%$ & $38 \%$ \\
\hline School & $19 \%$ & $15 \%$ & $28 \%$ & $14 \%$ & $20 \%$ \\
\hline Any relative & $11 \%$ & $17 \%$ & $9 \%$ & $10 \%$ & $11 \%$ \\
\hline Any other source & $25 \%$ & $29 \%$ & $33 \%$ & $29 \%$ & $30 \%$ \\
\hline $\mathrm{N}$ & 53 & 48 & 99 & 99 & 299 \\
\hline \multicolumn{6}{|l|}{ Husbands: } \\
\hline Newspaper/magazine & $33 \%$ & $12 \%$ & $40 \%$ & $27 \%$ & $30 \%$ \\
\hline Radio & $69 \%$ & $58 \%$ & $80 \%$ & $86 \%$ & $77 \%$ \\
\hline Television & $81 \%$ & $52 \%$ & $79 \%$ & $81 \%$ & $75 \%$ \\
\hline Books & $40 \%$ & $28 \%$ & $34 \%$ & $12 \%$ & $27 \%$ \\
\hline School & $28 \%$ & $10 \%$ & $23 \%$ & $15 \%$ & $19 \%$ \\
\hline Any relative & $7 \%$ & $12 \%$ & $10 \%$ & $8 \%$ & $9 \%$ \\
\hline Any other source & $34 \%$ & $38 \%$ & $28 \%$ & $24 \%$ & $29 \%$ \\
\hline $\mathrm{N}$ & 88 & 100 & 207 & 204 & 599 \\
\hline
\end{tabular}

Note: Most mentioned source shown in bold for each column within each panel. 
Except in the urban colony areas, married women nominate grandmothers as the most appropriate source for sex education. In Bangladesh, it is traditional for grandmothers to advise young women about menstruation. However, a media source (newspaper) is the most preferred source for well-off unmarried girls in urban areas, while female friends are the most preferred sources for unmarried girls in both the urban slums and well-off rural areas, and for married adolescent women in the urban colony areas. The remaining categories of adolescent women all nominate grandmothers more than any other source.

It is very notable that school-based sex education programs appear to attract little support. The general impression is that women prefer to receive their information from traditional sources and personal contacts or else from written material, while men prefer the public electronic media. The fact that there are differences between males and females should not be a policy concern, because any proposed sex education program would have components directed at boys and girls separately. It is also important to note that the overwhelming majority of married female respondents discuss sex with their husbands (76 per cent of married female respondents, ranging from 52 per cent in the urban slums to 87 per cent in well-off rural areas), so that education programs directed primarily at men can be designed to incorporate information intended to be shared with their wives.

The focus group discussions confirmed these patterns of response and difference between female and male respondents. There was noticeable variation among the female focus groups, with some promoting the roles of female relatives, others giving a prominent role to mass media, and others showing little agreement about any appropriate source, although there was strong agreement that sex education should be given in all groups. There was little mention of educational institutions or family planning field workers.

A role for institution-based sex education programs, meaning school programs, is much more prominent in the views expressed by service providers, guardians and community leaders, who were asked to recommend the most appropriate ways to conduct such a program. The source most commonly nominated by service providers was radio/television, while for guardians it was relatives and for community leaders it was educational institutions. The lack of uniformity indicates that a progam with several strands is likely to be the most approprite.

\section{Table 10}

\section{Recommended Sources of Sex Education by Service Providers, Guardians and Community Leaders (\%)}

\begin{tabular}{|l|c|c|c|}
\hline Source of Sex Education & Service Providers & Guardians & Community Leaders \\
\hline Within family & 24.0 & 22.0 & 23.0 \\
Relatives & 17.0 & 39.0 & 17.0 \\
Meetings/seminars & 31.0 & 14.0 & 23.0 \\
Print media & 39.0 & 26.0 & 32.0 \\
Radio/television & 55.0 & 37.0 & 43.0 \\
Educational institutions & 47.0 & 20.0 & 48.0 \\
Other & 36.0 & 16.0 & 34.0 \\
\hline N & 98 & 94 & 141 \\
\hline
\end{tabular}




\subsection{REPRODUCTIVE HEALTH}

'Reproductive' health is a crucial part of general health; not only is it a key element of health during adolescence and adulthood, it also sets the pace for health beyond the reproductive years for both women and men and has pronounced inter generational effects (Beijing Conference, Ref. 8). One of the main problems in achieving good reproductive health is the socio-cultural impediment on access to effective information on sexuality and reproductive health by the adolescents. Almost all the adolescents and the husbands had very poor knowledge of the reproductive organs. The current study specifically attempted to assess the level of knowledge of the adolescents and the husbands on the symptoms, mode of transmission or infection and the measures for prevention of STDs, RTIs and AIDS.

\subsubsection{Symptoms of STD, RTI and AIDS}

For this section of the questionnaire, a list of correct symptoms was precoded. The respondents were asked to name symptoms without any prompting. The symptoms of STDs that were on the list include ulcer in the sex organs; burning sensation during micturition; pus discharge through the genital tract; pain in the lower abdomen, and fever. The overall distribution of the responses showed that about half of the respondents (48 percent) could not identify a symptom correctly, 11 percent identified one symptom, 22 percent identified two, and 19 percent identified three or more symptoms of STDs correctly.

The precoded symptoms of RTIs that were used included white discharge; vaginal itching; pain in the abdomen; burning micturition and menstrual problems. The overall distribution of the responses on RTI symptoms showed that 62 percent of the respondents gave no response or incorrect answers; less than one-tenth ( 9 percent) gave one correct answer, 13 percent identified two symptoms correctly and 11 percent of the respondents identified three or more symptoms.

The symptoms of AIDS used in the study included ulcer in different parts of the body; cough; body-ache; gradual deterioration of health; anemia, and loss of immunity. Among the respondents in this study, 64 percent either did not give any response or could not correctly identify any of the symptoms associated with the disease, 16 percent could give one correct response, 13 percent could give two, and 5 percent gave three or more symptoms of AIDS.

Table 11 shows the distribution of the adolescents and husbands by status of identifying one or more of the symptoms of STD, RTI and AIDS correctly. The overall levels of knowledge by each category of respondents are reported, because the inter-group (category of respondents) differences by spatial (urban and rural) and economic status (well off and slums/poor) were not significant. 
Table 11

Distribution (\%) of respondents by correct knowledge of one or more symptoms of STD, RTI and AIDS

\begin{tabular}{|l|l|l|l|}
\hline Categories of Respondents & STD & RTI & AIDS \\
\hline Female Unmarried, $\mathrm{n}=341$ & 29.0 & 45.0 & 45.0 \\
Female Married, $\mathrm{n}=621$ & 35.0 & 57.0 & 29.0 \\
Male unmarried, $\mathrm{n}=299$ & 56.0 & 10.0 & 42.0 \\
Husbands, $\mathrm{n}=599$ & 80.0 & 27.0 & 28.0 \\
\hline
\end{tabular}

The female adolescents demonstrated better knowledge on the symptoms of RTIs than on the symptoms of STDs. On the other hand, the male adolescents and the husbands showed better knowledge on the symptoms of STDs than on RTIs. Unmarried adolescents, whether male or female, showed better knowledge on AIDS than the married adolescents and the husbands.

\subsubsection{Transmission (Infection) of RTI, STD and AIDS}

The processes of transmission of STDs, identified by the respondents, were sexual contact with the affected person; pregnant mother to baby; through blood transfusion; and sharing the syringe. The overall distribution of the responses showed that more than half (54 percent) of the respondents could not identify a mode of transmission correctly, while 36 percent identified a single process of transmission correctly, and 9 percent identified two processes correctly. The processes of transmission of RTI identified by the respondents included lack of cleanliness; intercourse during menstruation; non-aseptic delivery; and through abortions/MR. In this study, 70 percent of the respondents gave no answer or incorrect responses, while more than one-fifth ( 22 percent) gave a single correct response, 7 percent identified two processes of transmission correctly and one percent identified three or more processes. The processes of transmission of AIDS identified by the respondents included sexual contact with the affected person; homosexuality; through blood transfusion; pregnant mother to baby; and sharing of the syringe. The overall distribution of the responses revealed that more than two-thirds ( 66 percent) of the respondents could either not identify the correct response or did not give any response at all; while 25 percent gave a single correct response, 6 percent gave two correct responses and 2 percent gave three or more correct responses.

\section{Table 12}

Distribution of respondents by status of giving one or more correct response on the process of transmission of STD, RTI and AIDS

\begin{tabular}{|l|c|c|c|}
\hline Respondents & STD (\%) & RTI (\%) & AIDS (\%) \\
\hline Female Unmarried & 18.0 & 29.0 & 34.0 \\
Female Unmarried & 21.0 & 42.0 & 22.0 \\
Male Unmarried & 51.0 & 9.0 & 42.0 \\
Husbands & 76.0 & 23.0 & 34.0 \\
\hline
\end{tabular}


The female adolescents demonstrated better knowledge about the processes of transmission of RTI compared to their knowledge on STDs. On the other hand, the male adolescents and the husbands showed better knowledge on the processes of transmission of STDs than that on RTIs. Unmarried adolescents, males or females, and husbands demonstrated better knowledge on the processes of transmission of AIDS than the female married adolescents.

\subsubsection{Prevention of RTI, STD and AIDS}

The measures of prevention of STDs, precoded for the respondents were avoiding sex with multiple partners; using condoms; using disposable syringe; and through health education. The overall distribution of the responses showed that more than half (55 percent) of the respondents could not identify a response on preventive measure correctly, while 30 percent identified a single measure of prevention correctly; 12 percent identified two measures correctly; and two percent identified three or more measures. The measures of prevention of RTI identified by the respondents included maintaining cleanliness; safe delivery/abortions/MR; through health education and using condoms. The overall distribution of the responses showed that 70 percent of the respondents gave no or incorrect response, while less than one quarter (24 percent) gave a single correct response, and 3 percent identified two measures of prevention correctly. The measures of protection from AIDS identified by the respondents included avoiding sexual contact with affected person; avoiding multiple partners; testing blood before transfusion; using condoms; using disposable syringe, and through health education. The overall distribution of the responses revealed that more than two-thirds (67 percent) of the respondents could not either identify the correct response or did not give any response at all; while 21 percent gave a single correct response, 8 percent gave two correct responses and 3 percent gave three or more correct responses.

\section{Table 13}

Distribution of respondents by status of giving correct or no response on the measures of prevention from STDs, RTI and AMDS

\begin{tabular}{|c|c|c|c|c|c|c|}
\hline \multirow[t]{2}{*}{ Respondents } & \multicolumn{2}{|c|}{ STD Responses \% } & \multicolumn{2}{|c|}{ RTI Responses \% } & \multicolumn{2}{|c|}{ AIDS Responses \% } \\
\hline & Yes & No & Yes & No & Yes & No \\
\hline $\begin{array}{l}\text { Female Unmarried } \\
\mathrm{N}=341 \\
\text { Female Married }\end{array}$ & 17 & 83 & 33 & 67 & 35 & 65 \\
\hline $\begin{array}{l}\mathrm{N}=621 \\
\text { Male Unmarried }\end{array}$ & 21 & 79 & 43 & 57 & 23 & 77 \\
\hline $\begin{array}{l}\mathrm{N}=299 \\
\text { Husbands }\end{array}$ & 51 & 49 & 10 & 90 & 40 & 60 \\
\hline$N=599$ & 75 & 25 & 25 & 75 & 33 & 67 \\
\hline
\end{tabular}

The female adolescents demonstrated better knowledge on the measures for prevention of RTI compared with their knowledge on STDs. On the other hand, the male adolescents and the husbands had better knowledge on the measures of prevention of STDs than that on RTI. 
Unmarried adolescents, males or females, and husbands showed better knowledge on the measures of protection of AIDS than the married female adolescents.

The findings of the FGDs on adolescents' knowledge of symptoms, process of transmission and the measures of prevention of STDs, RTI and AIDS were comparable with those of the survey findings. However, the FGDs revealed that the respondents were also victims of serious misinformation/myths due to cultural prejudices/practices. The myths included beliefs in unknown or 'supernatural' influences, to isolation of persons, specially suffering from AIDS.

A question was asked to assess the level of knowledge of the guardians (94), community leaders (141), and the service providers (98) on the factors that cause STDs, RTIs and AIDS:

\section{Table 14}

Distribution of the guardians, community leaders and service providers by status of knowledge on transmission of STDs, RTIs and ADS Yes: Know the reason and NO: Don't Know the reason

\begin{tabular}{|l|cc|cc|rr|}
\hline Categories of Respondents & \multicolumn{2}{|c|}{ STD (\%) } & \multicolumn{2}{c|}{ RTI (\%) } & \multicolumn{2}{c|}{ AIDS (\%) } \\
& Yes & No & Yes & No & Yes & No \\
\hline Guardians: & 20 & 80 & 31 & 69 & 34 & 66 \\
Community Leaders: & 48 & 52 & 47 & 53 & 51 & 49 \\
Service Providers: & 66 & 34 & 47 & 53 & 74 & 26 \\
\hline
\end{tabular}

Knowledge of the service providers was observed to be better than those of the guardians and the community leaders. About two-thirds of the service providers could specify the reasons for STDs (66 percent) and AIDS (74 percent). Regarding RTI, the knowledge of the community leaders and service providers were comparable ( 47 percent). Generally the level of knowledge of the community leaders was observed to be much better than that of the guardians.

The results of the follow-up intensive interviews revealed that a number of respondents themselves were suffering from symptoms related to STDs and RTIs. Table 15 identifies the proportion of the respondents affected by symptoms of STDs and RTIs .

\section{Table 15}

Distribution of adolescents and husbands by prevalence of symptoms of STDs and RTIs

\begin{tabular}{|c|c|c|}
\hline \multirow[t]{2}{*}{ Categories of Respondents } & \multicolumn{2}{|c|}{ Percent of Respondents with Symptoms } \\
\hline & STDs & RTIs \\
\hline Female unmarried $\mathrm{n}=55$ & 3.0 & 45.0 \\
\hline Female Married $\mathrm{n}=58$ & 5.0 & 43.0 \\
\hline Male Unmarried $\mathrm{n}=48$ & 21.0 & 0 \\
\hline Husbands $\quad \mathrm{n}=57$ & 39.0 & 0 \\
\hline $\mathrm{n}=218$ & & \\
\hline
\end{tabular}


Qualitative interviews were conducted by a team of investigators consisting of doctors (male and female) and other experienced field supervisors-cum-interviewers. In selected cases, physical check up by the doctors was performed with consent of the respondents. The results revealed a high level of prevalence of RTIs among the female adolescents irrespective of marital status. The prevalence of STDs was also observed to be high among both unmarried male adolescents ( 21 percent), and the husbands ( 39 percent). Males also affirmed their indulgence in both extra and premarital sex.

\subsection{MARRIAGE}

The results of this study reveal that the traditional practice of early marriage is still common in this country. The mean age at marriage for the female married adolescents interviewed was 14.8 years and the mean duration of marriage about one year. Out of the 621 female married adolescents (aged 15-19) interviewed, 8 percent were aged between only 9 and 12 at the time of their first marriage, 55 percent were between 13 and 15 , and 37 percent between 16 and 19 .

\section{Table 16}

Distribution of age at marriage by geographical/socio-economic status

\begin{tabular}{|l|c|c|c|c|c|}
\hline \multirow{2}{*}{ Age Groups } & \multicolumn{2}{|c|}{ Urban } & \multicolumn{2}{c|}{ Rural } & \multirow{2}{*}{$\begin{array}{l}\text { Total } \\
\end{array}$} \\
\cline { 2 - 5 } & Colony (\%) & Slum (\%) & Poor (\%) & Well-off (\%) & \\
\hline $9-12$ & 2.9 & 10.2 & 11.1 & 5.7 & 7.8 \\
$13-15$ & 45.0 & 62.6 & 60.4 & 50.7 & 55.0 \\
$16-19$ & 51.0 & 25.2 & 28.5 & 43.5 & 36.7 \\
$20+$ & 1.0 & 1.9 & 0 & 0 & 0.5 \\
\hline Total & 100 & 100 & 100 & 100 & 100 \\
\hline N & 104 & 107 & 207 & 209 & 627 \\
\hline
\end{tabular}

As one would expect, the rural poor are most likely to get married at an early age followed by the urban slum dwellers, rural well-off and colony residents. Those who got married at a relatively later age are more likely to have completed more years of education. Only 4.6 percent of the female married respondents stated their occupation to be 'students' compared with 67.7 percent of unmarried female adolescents. Hence for girls who are in school, marriage marks the end of their education. In this culture it is almost impossible for most girls to be a 'housewife' with the myriad household responsibilities that the role entails and at the same time continue with school. Of the 621 married adolescents in the study, 92.9 percent categorized their occupation as 'housewife'. Delaying marriage will have a two-fold effect on a girl's fertility. Firstly studies show that if marriage is delayed by staying in education, the survival chances of the child of the educated mother are improved greatly. Secondly, delaying marriage and consequently the first birth can have a significant impact on a woman's total fertility.

The mean and median ages at marriage for the female married adolescents in the study were 14.8 years and 14.3 years respectively. The corresponding figures for the husbands of these female adolescents who were interviewed were 23.0 and 22.2 years. This gives a mean age difference of 8.2 years between the married adolescents and their 
husbands in this study which is in agreement with the findings from the secondary analysis of the 1993-94 Bangladesh Demographic and Health Survey (BDHS) data on adolescents (Kamal et al., 1996).

\subsubsection{Perception of Marriage}

Questions were asked to assess how present day adolescents feel about the traditional system of 'arranged marriage', and about marriage in general. Almost 50 percent of the total 1860 male and female respondents said that a girl should get married after completing her education although it wasn't specified whether 'education' in this context referred to primary, secondary or higher education. A handful, 4 percent, believed that girls should be financially stable, in other words, be in formal employment before getting married. Twenty-seven percent were of the view that girls should go by the parents' wish as far as marriage is concerned. Finally there was a category of 'liberal' respondents, 20 percent, who felt that a girl should only get married when she finds the partner of her choice.

Similarly among the female adolescents who were already married, 80 percent said that they were married to the spouse of their parents'/guardians' choice and only 12 percent had married the person they liked and the remaining 8 percent had married the person of their choice with their parents'/guardians' consent. On the other hand, among the husbands who were interviewed, 34 percent said that they were married to the girl of their choice whereas in 55 percent of the cases, the partner selection was made by parents/guardians. The remaining husbands had married the girl of their as well as their parents'/guardians' choice.

The mean ideal age at marriage recommended by both married and unmarried respondents of both sexes was 19.0 years for girls and 25.5 for men. According to the female unmarried and married adolescents, the mean ideal age at marriage was 19.8 and 19.3 years, respectively. As pointed out earlier in the discussion, the actual female mean age at first marriage for this study group was 15 years which gives a gap of over 4 years between the actual and ideal age at first marriage! This indicates that there is still considerable social pressure on girls to get married at an early age which may be 'lightened' if not removed altogether, by creating viable, acceptable educational and economic options for young girls in the country.

When asked what should be the age difference between the husband and the wife (traditionally the husband is older), the following picture was revealed:

\begin{tabular}{|l|c|c|}
\hline \multicolumn{3}{|c|}{ Table 17 } \\
\multicolumn{2}{|c|}{ Ideal age difference between husband and wife } \\
\hline No age difference & N (Respondents) & Percent (\%) \\
Less than 2 years & 9 & 0.5 \\
Less than 5 years & 133 & 7.1 \\
Less than 7 years & 989 & 53.2 \\
7 years or above & 454 & 24.4 \\
No response & 269 & 14.5 \\
\hline TOTAL & 6 & 0.3 \\
\hline
\end{tabular}


As the above table indicates, the majority of the respondents believe that an age difference of "less than five years" between husband and wife is ideal.

\subsection{FERTILITY}

As adolescent girls get married and assume regular sexual relations, they become exposed to the risks of conception and childbearing. Analysis of the results of this study suggests that despite the elevated health risks associated with adolescent pregnancy/childbearing, the overwhelming majority of the study population had at least one pregnancy. To be exact, 457 out of the 621 married adolescents studied (73.6 percent) had a total of 623 pregnancies. The outcome of these 623 conceptions was not necessarily full-term pregnancies or livebirths as later analysis will reveal. The total of 623 pregnancies comprised the following:

\begin{tabular}{|c|c|c|}
\hline \multicolumn{3}{|c|}{ Table 18} \\
\hline \multicolumn{3}{|c|}{ Distribution of pregnancy outcomes among married adolescents } \\
\hline Currently Pregnant & 101 & $16.2 \%(\mathrm{~N}=621)$ \\
\hline Outcome & $\mathbf{N}$ & Percentage \\
\hline Menstrual Regulation (MR) & 22 & 4.2 \\
\hline Spontaneous Abortion & 28 & 5.3 \\
\hline Stillbirths & 26 & 4.9 \\
\hline Living Children & 413 & 79.1 \\
\hline Died after Birth & 33 & 6.3 \\
\hline TOTAL & 522 & 100 \\
\hline
\end{tabular}

The questions on pregnancy history in this survey asked for ' $\mathrm{YES} / \mathrm{NO}$ ' responses only and did not probe for details, that is, the number of each event, stillbirths, spontaneous abortions, was not recorded. According to the above table, 101 of the respondents, or 16.2 percent of the study sample said that they were pregnant at the time of the interview. In calculating the subsequent rates of MR, stillbirths, etc., the 101 current pregnancies were excluded from the number of total pregnancies because we do not know what the outcome of these pregnancies will be. Hence the denominator for all the rates except the category 'currently pregnant' was $\mathbf{5 2 2}$.

The rate of fetal wastage or intrauterine mortality is normally calculated by adding the rates of spontaneous abortion (fetal deaths before the twenty-eight weeks of gestation) and stillbirths (fetal deaths after that date). The rate of fetal wastage among adolescents, estimated using this study results, is about 10 percent which seems rather low; the average for the country is 12 percent or 120.1 per 1000 pregnancies (Demographic Surveillance System, MATLAB, 1994). As suggested by Bongaarts and Potter (1983), " the intrauterine mortality rates vary substantially with age; teenagers may have higher rates than women in their twenties ". An explanation for the low observed rate of fetal wastage could be that not enough probing questions were asked. 
Regarding the number of living children, 282 respondents had one, 61 had two and 3 had three living children at the time of interview.

The actual mean age at first birth was 16.0 years for married adolescents aged 1519 in the study. The mean ideal spacing between marriage and first birth was 3.6 years although there were variations by marital status. According to the never married and currently married female adolescents, the mean ideal spacing between marriage and first birth was almost identical, 3.7 and 3.8 years respectively. However the male unmarried adolescents stated an average ideal spacing of 4.8 years, and the husbands of the married adolescents, 2.8 years.

Although 73.6 percent of the respondents had at least one pregnancy, 65.2 percent actually had a delivery (where the infant could still be living, died after birth, or a stillbirth). About 30 percent of these married adolescents were aged between 12 and 15 at the time of the first delivery/birth. The obvious conclusion one draws from this data is that in order to delay the first birth, the age at first marriage has to be increased. Otherwise soon after a girl gets married, irrespective of her age, she is under social pressure to produce a child to prove her fecundity.

\subsection{USE OF FAMULY PLANNING}

A possible explanation for the relatively high conception rate among young adolescents could be that young couples do not have reliable information on, or easy access to, family planning.

\subsubsection{Knowledge of family planning}

First, looking at their knowledge on family planning methods, the levels are far below the trends observed in the country in the 1993-94 BDHS.

Table 19

Distribution of respondents' knowledge by name of family planning methods

\begin{tabular}{|l|c|c|c|}
\hline \multirow{3}{*}{ Method } & All Respondents & $\begin{array}{c}\text { Married Female } \\
\text { aged 15-19 - } \\
\text { (Unprompted) }\end{array}$ & $\begin{array}{c}\text { Currently Married } \\
\text { Female (10-49) }\end{array}$ \\
\hline Pill & $(\mathbf{N = 1 8 6 0 )}$ & $(\mathbf{N}=621)$ & 1993-94 BDHS \\
IUD & 98.4 & 99.7 & 99.5 \\
Condom & 23.8 & 44.6 & 90.0 \\
Injection & 86.7 & 83.7 & 87.4 \\
Ligation & 43.4 & 68.0 & 96.6 \\
Vasectomy & 33.6 & 50.2 & 99.0 \\
Safe Period & 5.8 & 6.6 & 83.1 \\
Norplant & 2.5 & 2.7 & 65.0 \\
Foam/Jelly & 2.8 & 4.0 & NA* $^{*}$ \\
\hline
\end{tabular}

NA* - Not Asked 
Among the reasons that could be put forward to explain the low levels of knowledge on FP among the respondents, one is that the DHS figures include prompted responses. Also, when taking the aggregate responses of all categories of respondents in the study, the low levels of knowledge generally observed among unmarried boys and girls brought down the total average level of knowledge on each method. The distribution of knowledge of the individual categories of unmarried female and male was generally lower than that of the married female adolescents and their husbands. The unmarried female adolescents seemed to be better informed than their male counterparts as far as names of FP methods were concerned.

The results of the focus group discussions (FGD) confirmed this finding. FGD results also revealed that knowledge on FP methods was higher in the rural than in the urban areas and adolescents (of both sexes) from better-off socio-economic backgrounds had the highest knowledge. Among the female groups studied, the categories 'unmarried urban school-going' seemed to be the least informed, followed by 'married urban poor'. This is probably because of the low coverage of the FP program in the urban slum areas. The level of knowledge on FP methods among all the male groups studied was lower than their female counterparts which could be associated with the program's main focus so far on 'women'.

The most striking feature about the above table is the level of knowledge observed for the male sterilization method, vasectomy, and safe period, 5.8 percent and 2.8 percent, respectively, among all respondents, as well as the married adolescents. Even the FGD results showed that the level of knowledge on the clinical methods like sterilization and IUD is generally low.

The mean number of sources of FP that the respondents could name was 3 for married male and female, and 2 for unmarried male/female. The most widely known source of FP was shop/pharmacy (94.3 percent) followed by FWA (69.2 percent). Almost all the respondents could name at least one FP method related side-effect and the most common was nausea/dizziness. 'Doctor' was the most widely known source of treatment for FP side-effects/complications, followed by THC and hospital and this is in agreement with the FGD results.

According to the survey results, knowledge of methods, sources and side-effects was highest among female married adolescents of higher socio-economic status (both urban and rural) and lowest among the urban slum dwellers. However the FGD results showed that the unmarried school-going adolescents of both sexes had the highest knowledge on the sources of FP. This could be attributed to the fact that rural adolescents are in contact with their married peers whereas the urban way of life is more 'isolated'. Fieldworkers (FWAs) and doctors (hospitals, clinics) were the most commonly mentioned sources of FP in the focus group discussions with unmarried adolescents. The female unmarried adolescents seemed to be better informed on the side-effects of FP methods than their male counterparts. 


\subsubsection{Current use of family planning}

The level of current use of the various family planning methods among the 621 female married respondents in the study was as follows:

\begin{tabular}{|l|c|c|}
\hline \multicolumn{3}{|c|}{ Table 20 } \\
\hline \multicolumn{3}{|c|}{ Distribution of married females aged 15-19 } \\
planning \\
\hline Method & CPR among (15-19) in & 1996-97 BDHS, \\
& this study, N=621 & CPR among (15-19) \\
\hline Pill & 27.2 & 17.9 \\
IUD & 3.2 & 1.0 \\
Condom & 7.4 & 4.3 \\
Injection & 2.3 & 4.4 \\
Ligation & 0.2 & 0.0 \\
Vasectomy & 0.6 & 0.1 \\
Safe Period & 1.4 & 3.2 \\
Norplant & 0.2 & NA* \\
Others & NA* & 2.0 \\
\hline TOTAL & 42.5 & 32.9 \\
\hline
\end{tabular}

NA* - Not asked

It is interesting that although the level of knowledge on FP methods is considerably lower among the respondents in this study, the contraceptive prevalence rate (CPR) of 42.5 percent for the age group 15-19 is much higher than the 1993-94 and 1996-97 DHS results, 24.7 percent and 32.9 percent, respectively. One possibility is that differences in the way questions were asked and the timing of the surveys partly account for the big difference in the CPR calculated in this study and the DHS figures. As the above table shows, the high level of pill use among the female married adolescents, 27.2 percent of the 621 respondents, seems to be contributing most to the high total CPR for this age group. The figures for IUD and condom use are higher for the adolescents in this study than the 1996$97 \mathrm{BDHS}$ figures. What is surprising is the lower level of use of the traditional method of birth control, namely safe period compared with the 1996-97 BDHS. The level of current use of the safe period and injectables is higher in the DHS than in this study. Contraceptive prevalence was highest among the urban colony residents (63 percent) and lowest among urban slum dwellers (31 percent).

\subsubsection{Fall in the use of Traditional Methods of family planning}

The traditional view was that young couples are least likely among all age groups to use family planning, and previous findings from the BFS and CPS surveys confirmed this view. There are various beliefs/myths regarding the fertility inhibiting properties of some of the modern methods of contraception. For example, it is believed that taking the oral contraceptive pill before having a child can result in complications during delivery or can even make a woman infertile (Gray et al., 1997). In a situation where there is limited access to accurate/reliable information on family planning, myths of such nature often discourage young couples from controlling their fertility before having at least one child. 
Study results have shown that the few couples that did wish to delay their first child, relied on traditional methods like safe period and withdrawal (coitus interruptus).

Results from the secondary analysis of the 1993-94 BDHS data on adolescents are in agreement with the results of this study; young, newly married couples are increasingly adopting family planing methods and they seem to be moving away from the traditional methods and adopting modern methods of birth control. Between 1975 and 1993-94, the use of the traditional methods of birth control among married female aged below 20 increased from 1.5 percent to 5.8 percent and that of modern methods increased from 3.0 percent to 18.8 percent.

Of the current users of FP, 51.1 percent stated that they were suffering from one or more side-effects. Among the complaints made by the adolescents, dizziness was the most common, followed by nausea and weakness. Only 26 out of the total number of 264 users, or about 10 percent, sought treatment for their problems. Their treatment mainly involved going to a health provider, followed by changing the method.

This has important policy implications. Counseling has to be provided on the appropriate choice of methods for low parity or nulliparous adolescents/women as well as the management of side-effects in order to prevent these growing numbers of adolescent users of FP from dropping out.

Looking at FP use and the duration of marriage, FP use was highest (21.7 percent) among the female respondents who had been married for 3-5 years. For those who had been married more recently or for a longer duration, the extent of FP use was not as high :

\begin{tabular}{|l|c|}
\hline \multicolumn{2}{|c|}{ Table 21} \\
Distribution of family planning use by duration of marriage \\
\hline Duration of Marriage (Years) & Percent using family planning \\
& (N=621) \\
\hline 0-0.9 years & 4.5 \\
1.0-2.9 years & 9.5 \\
3.0-5.9 years & 21.7 \\
6.0 years and above & 6.8 \\
\hline TOTAL & $\mathbf{4 2 . 5}$ \\
\hline
\end{tabular}

One would expect the level of FP use to be highest among those who have been married for 6 years and above on the assumption that these women might have had one or more pregnancies during those six years of exposure and are more likely to be spacing or delaying the next pregnancy than those who have been married for a shorter duration. According to the above table, that is not the case, the level of FP use among the adolescents who had been married for 6 or more years ( 6.8 percent) is not as high as that among the group whose marriage duration was between 1 and 2 years ( 9.5 percent). 


\subsubsection{Spousal communication regarding family planning use}

Finally the results of this study reveal that a large proportion of the female married respondents, almost 79 percent, communicate with their husbands regarding family planning use. Advocates of "male involvement in family planning" should find this finding encouraging. It is tempting to think of this impressive figure of 79 percent as a positive social/cultural change on the grounds that with the increasing 'openness' of the society and the diffusion of western/modern ideas at all levels in the society, there is more spousal communication among the young couples of today than among older generations. However the FGD results reveal a different picture as far as interspousal communication is concerned; very few adolescent wives had talked with their husbands about FP. The majority of the adolescents interact with their friends, peers and cousins and in the case of the married adolescents, their sisters-in-law, on FP related issues.

Among the reasons one could think of to explain this discrepancy in the two results, the obvious one seems to be the inherent strengths and weaknesses of quantitative and qualitative methods of research. It is an established fact that in a survey interview, the interviewees often feel obliged to give all 'positive' responses or responses that they feel the interviewer is 'expecting'. It is possible that in this survey on adolescents, a lot of the young, married respondents said 'YES' when they were asked if they talked with their husbands about FP use because the interviewees felt that they should be saying 'YES' to that question. However, in the FGDs, which were conducted on a different sample of female married adolescents with the same socio-economic background, the participants probably felt more comfortable being in the presence of peers. As a result, they could open up and talk honestly about the actual extent of spousal communication regarding FP use. Also, since the FGDs involved more probing questions on this topic than the survey questionnaire, it is safe to conclude that there is still little spousal communication regarding FP use even among the younger generations.

\subsection{MOTHER AND CHILD HEALTH (MCH)}

\subsubsection{Ante-natal care}

Out of the total married female respondents who ever had any full-term pregnancies, about 85 percent claimed to have received some kind of ante-natal care. The level of reported ante-natal care was more or less the same across the different geographic/socio-economic groups. Among these adolescents who had ever been pregnant, the majority, 63 percent, received TT shots (compared with 79 percent for those aged below 20 in the 1996-97 BDHS), 29 percent went for physical check-ups, and the remaining respondents mentioned checking blood pressure, taking iron tablets and 'others' as other kinds of ante-natal care that they received. Forty-three percent of them said that they had been to a 'hospital' for ante-natal care, 12 percent had been to a FWC, 4 percent mentioned clinic and the remaining 41 percent said 'other'. Questions were not asked on the number of visits made.

According to the 1996-97 BDHS results, the coverage of ante-natal care has not increased since the 1993-94 DHS. The proportion of women of reproductive age (10-49) who received some ante-natal care from a doctor, nurse, midwife or 'other' was 26 percent according to these two DHS surveys and the level of care for adolescents was slightly higher 
(31.1 percent, 1993-94 BDHS). For this study, the proportion of pregnant adolescents who received care from the same sources was much higher. The explanation for this discrepancy probably lies in the respondents' perception of ante-natal care. A large proportion, 41 percent, of those who reported receiving ante-natal care said that they received their care from 'other' sources and not the standard ones like health centers. Although detailed questions were not asked, it is possible that some of the respondents were referring to things like special diet for the pregnant mother (as often advised by older relatives), social restrictions on her physical movements, going to traditional healers, wearing special amulets to keep away evil spirits, and the like, as ante-natal care.

As far as the place of delivery is concemed, the overwhelming majority of the adolescent mothers gave birth in their own homes - 61.0 percent of the colony dwellers, 77.4 percent of slum residents, 90.1 percent of adolescent mothers in the 'poor village' areas and 85.9 percent in the village well-off areas. Between 16.0 and 18.0 percent of the adolescent mothers in the urban areas and 8.0 to 11.0 percent in the rural areas, went to a hospital for delivery.

The following table shows that the majority of the adolescent mothers did not avail of medical care during delivery despite being at an elevated risk of hemorrhage and lifethreatening complications during delivery.

Table 22

Distribution (\%) of Female Married Adolescents by Type of Birth Attendant during Delivery

\begin{tabular}{|l|c|c|c|c|}
\hline & \multicolumn{4}{|c|}{ Geographic/Socio-economic Classifications } \\
\hline & $\begin{array}{c}\text { Colony } \\
(\mathbf{N = 6 4 )}\end{array}$ & $\begin{array}{c}\text { Slum } \\
\mathbf{N = 6 1 )}\end{array}$ & $\begin{array}{c}\text { Village (Poor) } \\
(\mathbf{N = 1 4 0 )}\end{array}$ & $\begin{array}{c}\text { Village (Well- } \\
\text { off) } \\
(\mathbf{N = 1 0 7 )}\end{array}$ \\
\hline Doctor & 32.8 & 11.5 & 8.6 & 9.3 \\
Relative & 15.6 & 22.9 & 27.8 & 16.8 \\
TTBA & 7.8 & 9.8 & 10.7 & 9.3 \\
TBA (dai) & 21.9 & 36.0 & 43.6 & 38.3 \\
FWV/Nurse & 15.6 & 11.5 & 5.7 & 20.6 \\
Others & 6.3 & 8.2 & 3.6 & 5.6 \\
\hline TOTAL & 100.0 & 100.0 & 100.0 & 100.0 \\
\hline
\end{tabular}

Almost 33 percent of colony residents were assisted by a doctor during delivery compared with 11.5 percent of slum dwellers and less than 10 percent of adolescents interviewed in the villages. The fact that little difference is observed between the poor and the relatively well-off adolescents in the village can probably be explained by the lower coverage of medical facilities in the rural areas. It is also possible that urban dwellers do not observe 'purdah' as strictly as the relatively more conservative village residents and therefore can avail of modern medical services outside home. The TBA or dai is still the most widely used type of birth attendant among the adolescents, except for colony dwellers. 
However, the majority of the adolescents, married or unmarried, and the husbands had recommended use of modern delivery services outside home. Among the married females, 71 percent of the urban colony residents and 54 percent of the rural well off group, recommended use of modern delivery services outside the home, while only one-third of the slum residents and the rural poor recommended the same. It is evident that not only the use of modern delivery services is low, it is also not an aspired service by at least the poor and the slum residents. Although the acceptance rates of TT in Bangladesh is high, the knowledge about the sequences and the interval of accepting TTs among the adolescents was not encouraging.

\subsubsection{Primary Health Care (PHC): Survey Findings}

Almost all the respondents, except those in the slums, reported awareness correctly about 3 EPI vaccines: DPT, Polio and Measles. The knowledge of EPI vaccines seemed to be relatively low among those residing in the slums and also among the husbands. The majority of the respondents, except the married females in the slums, could correctly mention the ideal onset of breastfeeding (immediately after birth). The most frequent answers given by the married females in the slums were offering breastmilk within 1-3 days and 7 days after birth of the baby. They lacked knowledge on colostrum and its importance. Exposure to television might have influenced such level of knowledge among all respondents, except those in slums, whose exposure to TV was very low. Correct knowledge on the interventions on diarrhea (including ORS) and night blindness, was universal among the respondents.

\subsubsection{FGD Findings: Knowledge About ORS and Immunization}

Most of the respondents, females or males, identified use of ORS with the incidence of diarrhea, vomiting, nausea, dehydration, weakness and loose motion. Many of the male groups specified use of ORS for rehydration. The knowledge of the female adolescents on ORS seemed to be a little less than their male counterparts. This could be due to the fact that the field workers (HAs) are mostly males.

Among the female participants in the FGDs, three groups: (i) rural married well off, (ii) those attending Health Service Centers in the rural areas, and (iii) married urban poor, demonstrated maximum knowledge on vaccines available for the diseases covered by EPI. Similarly, among the males, the school-going unmarried adolescents, and married urban well off, demonstrated maximum knowledge on EPI vaccines. Two female groups, unmarried school-going, both in rural and urban areas, and among the males, unmarried school-going adolescents in the urban areas, reported to have little knowledge on immunization. In the FGDs it was revealed that the female field workers of FP, belonging to GOB or NGOs, are one of the effective sources of dissemination of information on immunization in both urban and rural areas. The FGDs also revealed that knowledge of female adolescents on immunization was higher than their male counterparts. However, the school going adolescents were least conversant in immunization. This demonstrates weaknesses of the school health programs in the country.

\subsection{WOMEN'S EMPOWERMENT: SURVEY FINDINGS}

The head male member still seems to be the main decision-taker in the family. When the respondents were asked who, in their respective families, took major decisions regarding family 
matters like wife's or children's employment outside home, the predominant response was 'father' or 'husband', followed by 'both' the parents/spouse, and finally the female head of the household (mother or wife). It was interesting to see that even on matters like children's healthcare and decision on the purchase of daily foodstuff, the father or husband was the main decision-taker, followed by both the parents/spouse. Even for children's education, significant differences were not found, 21 percent of the respondents said that 'mother' was the prime decision-taker, followed by 'husband' (20 percent), and 'father' (19 percent).

The respondents were then asked about their opinion on whether the parents of girls would allow them to do certain things, for example, to be engaged in paid employment outside home. Over 50 percent of the respondents said that the mothers would allow, and less than one percent said that the fathers would give consent to a daughter's wish to work outside home. Finally there was a question which asked if a mother or wife should be allowed to take decisions on certain family matters. Only 21 percent of the respondents said that the female household head's decision should carry weight regarding financial matters compared with a response of 41 percent regarding children's education. When asked if the wife or mother should be involved in the decision-making process regarding who should contribute to the family income, only 24 percent said 'YES'.

The respondents were asked to cite any incidents of violence against women that they might have observed directly at any point in their lives. The majority of the adolescents, especially the married females, reported having seen violence against women. The most common form of violence reported was physical abuse of women, most often by the husband.

\section{Table 23}

Distribution of the respondents by frequencies of observation of the incidents of violence against women

\begin{tabular}{|l|c|c|c|c|}
\hline \multirow{2}{*}{ Categories of } & \multicolumn{2}{|c|}{ Urban (\%) } & \multicolumn{2}{c|}{ Rural (\%) } \\
\cline { 2 - 5 } Respondents & Colonies & Slums & Well Off & Poor \\
\hline Female unmarried & 53.0 & 67.0 & 70.0 & 65.0 \\
Female Married & 51.0 & 55.0 & 59.0 & 62.0 \\
Male Unmarried & 53.0 & 58.0 & 63.0 & 63.0 \\
Husbands & 73.0 & 68.0 & 61.0 & 67.0 \\
\hline
\end{tabular}

The level of observed violence against women (physical assault), as reported by the respondents, was very high, between 51 and 73 percent but this should not be interpreted as the prevalence of physical abuse against women because these incidents could have occurred many years before the survey as there was no time reference. The rural adolescents reported higher incidence of violence than their counterparts in the urban locations. The level of violence reported by the husbands interviewed in the study exceeded those by any other category of respondents. The incidence of violence was generally reported more by the poorer sections than by the residents of colonies and well-off locations. However the observed differences in violence against women between the poor and the well-off respondents were minimum. The most frequently cited reasons for violence were dowry, marital problems including infertility, temperamental maladjustment with husband or in-laws, extramarital sexual relations, etc. This 
was uniformly revealed by the results of FGD, and the interviews with the guardians, community leaders and the service providers. 


\section{CHAPTER 5}

\section{Policy Implications and Interventions}

Knowledge on reproductive health and sexual attitude and behavior is important to family planning researchers, policy makers and service providers, because these underlie virtually all the conditions that their programs address. However little is known about how the clients interpret their sexual and reproductive lives and what providers can do to help women gain more effective control over their reproductive and sexual lives (Zeidenstein and Moore, 1996). Sexuality is predominantly a social construct and primarily influenced by prescribed gender roles in the society. An understanding of the dynamics of sexuality, as correlates of reproductive health, facilitates designing of program strategies to overcome the impediments posed by the factors of demand for services, especially in the areas of maternal and reproductive health services. Future program interventions should attempt to design reproductive health programs that focus on human sexuality and gender concerns with an understanding of the socio-cultural context (Haider, 1996).

Adolescents constitute a large proportion (23 percent) of the population of Bangladesh; the current number of adolescents aged between 15-19 is 11 million, and many of them are married. Focusing the programs of reproductive health and family planning on married as well as unmarried adolescents is imperative for internalizing the behavior that supports the use of modern health care services for improving the quality of life. Besides, the sooner the adolescents pick up FP practices as a routine behavior, the greater are the prospects of slowing down the momentum effect of population growth after reaching replacement fertility. The current paper analyzes the level of knowledge, attitude and practices of the adolescents and the husbands, on reproductive health and sexuality, in the context of varying geographical, socioeconomic and demographic conditions of Bangladesh. This study report highlights the salient features of adolescent reproductive health in the country, underscoring the need for major policy and program interventions to accelerate participation of adolescents in the reproductive health care programs including family planning. The current paper presents critical findings on selected variables, such as media exposure, sexuality, reproductive health, marriage, fertility, use of $\mathrm{FP}, \mathrm{MCH}, \mathrm{PHC}$ and women's empowerment, primarily comparing the adolescents and husbands by varying geographical (urban-rural) and socio-economic (slums and rural poor versus colonies and the rural well off groups) backgrounds.

The results of the study provided an in-depth analysis of knowledge, attitude and practices of adolescents on sexuality and reproductive health. It does not provide any national rates. However, the sample size of the adolescents (1860) was large enough to generalize the findings for designing future program interventions. The primary focus of the study was adolescents aged between 15-19 years, married and unmarried. The study also included subsamples of husbands, guardians, community leaders and the service providers, who interplay an important influence on the adolescents. Complimentary data collection techniques, other than surveys, were employed in the study in order to allay the usual impediments of obtaining good quality data on sensitive topics like sexuality and reproductive health. 


\subsection{EXPOSURE TO MASS MEDIA}

Television, followed by radio, are popular media of mass communication for the adolescents. A very large proportion of the female unmarried adolescents both in the urban colonies (81 percent) and the rural well off population (74 percent) reported regular viewing of the television. Recent emergence of cable TV network may have contributed greatly to the urge for viewing TV among the young. The rates of regular TV viewing among the unmarried male and married female adolescents were also very high in the colonies (64-68 percent) and among the rural well off (54-60 percent) sections. The exposure of the slum dwellers to TV was relatively low (20-23 percent). Television can play a vital role in disseminating messages on social development including reproductive health and FP.

\subsection{SEXUALITY}

The issue of sexuality is seldom openly dealt with in a traditional society, social/cultural taboos prohibit or make it difficult to even initiate discussions on the subject. It becomes still more difficult when the discussions are held with adolescents and unmarried persons. The current study inquired about the risks of exposure of the respondents to sexual experiences in the survey, FGD and the intensive interviews. The specific questions were to determine the levels of direct personal experience of the respondents on sexuality and focused on both pre and extra-marital sexual experiences. Difficulties were faced in obtaining responses to questions on such 'sensitive' topics. However in an interpersonal situation, by involving the respondents in discussions on health issues, the 'atmosphere' was created for discussions on sexuality. The findings suggest that the males were more eager to discuss the subject describing their own personal experiences while the females preferred to discuss the subject projecting the experiences of friends and relatives.

The study results revealed that the majority of urban males had already experienced premarital sexual intercourse at all the single years studied (15 through 19 years), and large minorities of urban women, whether married or unmarried, had already experienced sexual intercourse by their late teens if they had not yet married. Premarital sexual intercourse seems to begin later for men in rural areas, and is at a very low level for women in rural areas.

With increasing duration of marriage, there was a significant increase in the proportion of husbands who acknowledged having had sexual intercourse outside marriage. In the urban areas, the 'husband' respondents were less likely to report their extra-marital experiences, but for all types of location, at least one in six men married for 5 or more years, acknowledged extra-marital experience. Of those husbands indulging in extra-marital sex, the majority, 71 percent, mentioned commercial sex workers. Very few female married respondents in the study reported their extra-marital experiences.

It is clear from these study results that there are pre and extra-marital sexual activities in the society, both in the urban and rural areas. The prevalence rates of STDs and RTIs are also high. It is imperative that sex education should constitute an integral component of both health and FP programs as well as the school curriculum.

Regarding puberty, perhaps the reason why so many ( 84 percent) of the female respondents reported shock, surprise and fright as the reactions after first menstruation is that 
they did not have accurate knowledge/information about the physical/emotional changes that their bodies were going through. Thirty-four percent of the respondents named 'friends' as the first source of information on menstruation. These 'friends' may be not that much older than the respondents and hence may not know much about puberty themselves. These 'friends' probably only informed the respondents about the physical changes characterizing puberty/menstruation, but not necessarily how to deal with such changes and hence the frightful reaction reported by the respondents. Therefore, female adolescents need factual, reliable information/education on puberty to help them be better prepared.

\subsection{REPRODUCTIVE HEALTH}

For the adolescents, socio-cultural barriers act as the main inhibitors for accessing information and services on reproductive health. Some of these were experienced during data collection, wherein the mothers-in-law were hesitant to allow their daughters-in-law to be interviewed. In general one-fifth to one-sixth of the respondents demonstrated knowledge on RTIs/STDs and AIDS (symptoms, transmission and prevention). The findings of the FGDs and the surveys on these topics were comparable. However, the FGDs revealed that the respondents could not obtain accurate information due to cultural prejudice/barriers. The follow-up intensive interviews with a sub-sample of adolescents and husbands revealed that the proportion of respondents suffering from the symptoms was high: 21-39 percent (males) for STDs and 43-45 percent (females) for RTIs. Given the high prevalence of RTI and STD and the poor level of knowledge on symptoms, transmission and prevention, it is of utmost importance to provide reproductive healthcare services to people of all ages which will in turn ensure sound general health.

\subsection{MARRIAGE AND FERTILITY}

Early marriage and childbearing are still common. There was a difference of 4.2 years between the actual mean age at first marriage ( 14.8 years) and the ideal mean age at marriage (19.0 years) among the female married respondents in this study. Again the observed mean age at first birth was 6.6 years lower than the ideal. About three-quarters of the study sample of female married adolescents had at least one pregnancy at the time of interview and 30 percent were aged between 12 and 15 at the time of first delivery/birth. Therefore the social pressures on girls to get married early and to have a child soon after marriage have to be removed. This can be done by educating adolescents and their guardians about the benefits of girls' education and also about the elevated health risks of adolescent mothers and their children.

\subsection{USE OF FAMILY PLANNING}

Young couples are increasingly adopting FP methods. Analysis of the results of this survey gave a CPR of 42.5 percent among the female currently married adolescents aged 1519. The preliminary results of the 1996-97 BDHS also suggest that the CPR for this age group has increased considerably; the increase for this age group 15-19 has been by 33.2 percent since 1993-94 compared with an increase of 10.3 percent for the age group 10-49 over the same time period. More adolescents use modern methods now than ever before where pill is the most widely used method followed by condom. The FP program has to provide these growing numbers of adolescent users of FP with counseling on the appropriate choice of methods as well as the management of side-effects in order to prevent them from dropping out. 


\subsection{MCH and PHC Services}

The coverage of TT shots among the adolescent mothers in this study was lower (63 percent) than the 1996-97 DHS figure (79 percent). Adolescent mothers still rely predominantly on traditional, untrained services during delivery/childbirth. About 33 percent of the adolescent mothers in the colonies availed of professional services (medical doctor) compared with 11.5 percent of those in the slums and less than 10 percent in the rural areas. However a much larger proportion of these married adolescents as well as unmarried male/female adolescents and husbands recommended use of modern medical services during delivery.

This information posits two distinct levels of interventions, they are:

i. Emphasizing the demand factors (socio-cultural and institutional changes) to accelerate the desire for modern delivery services through programmatic interventions simultaneous to changes in the existing traits and beliefs supporting delivery at home; and

ii. Establishing better RH/FP/MCH services for the unmarried adolescents in urban and rural areas, especially targeting the population in the slums and the rural areas.

The PHC services in the urban slums, compared to target populations in other locations or background, seem to be not as effective. The programs on EPI and breastfeeding for urban slum populations, addressing the needs of the married and unmarried adolescents, certainly demand further strengthening.

\subsection{WOMEN'S EMPOWERMENT}

Despite the ban on dowry, it is still one of the main causes of violence against women. Violence against women can be of different manifestations ranging from physical assault to psychological torture and gender inequities. All these affect primarily the health of the mother, specially the reproductive health status of the adolescents. This study also reveals that the role of the mother/wife in taking major family decisions is still small. Programs related to interventions through social mobilization, attempting to alter the existing status of women, especially that of the adolescent girls in the family and in the community, should form part of the regular strategies of the overall health sector programs. The participation of the women, who are the stakeholder in such interventions, is most critical.

States have advanced their chosen social, economic, and population agendas by implementing laws and employing practices that control women's reproduction. To gain autonomy, women must attain reproductive self determination, their path to many of life's opportunities (Cook, 1993). Unless the adolescents are informed about reproductive processes, sexual act, consequences of unsafe sex, and early marriage and childbearing, the prospect for future healthy reproductive life for them is threatened. A considerable gap exists between the policies government has proclaimed, and presumably committed themselves to, and the reality of women's lives. Women's reproductive health and status are influenced by several interrelated factors. It is, therefore, imperative to act simultaneously in several sectors to bring about changes in women's, including adolescents', lives and their health (Ross et al., 1996). 


\section{REFERENCE}

1. Ajayi A.A., Marangu T.L., Miller J., Paxman M.J., Adolescent Sexuality and Fertility in Kenya: A Survey of Knowledge, Perceptions and Practices, Studies in Family Planning, Volume-22, Number-4, July/August 1991.

2. Bangladesh Population Census 1991, volume 2: Union Statistics - Bangladesh Bureau of Statistics, Statistics Division, Ministry of Planning, Bangladesh (1993)

3. Barker G.K. \& Rich S. - Influences on Adolescent Sexuality in Nigeria and Kenya: Findings from Recent Focus Group Discussions, Studies in Family Planning, Volume23. Number-3, May/June 1992.

4. Bongaarts \& Potter - Fertility, Biology and Behaviour, Academic Press (1983).

5. Bruce J., Lloyd C.B., Women's Roles, Family and Gender Issues: Priorities For The Population Council, Mission and Mandate Environmental Scan.

6. Cook, J.R. - International Human Rights and Women's Reproductive Health, Studies in Family Planning, Volume-24, Number-2, Mar/Apr. 1993.

7. Dixon-Mueller R. - The Sexuality Connection in Reproductive Health, Studies in Family Planning, Volume-24, Number-5, Sept/Oct. 1993.

8. Draft-Reproductive Health in the Urban Sector-A working paper. UNFPA, Concerned Women for Family Planning, (August-1996).

9. Gray A., Chowdhury J.H., Caldwell B., Al-Sabir A. - Traditional Family Planning in Bangladesh, Population Council, Bangladesh (June 1997).

10. Haider S.J., Report of The National Workshop on Reproductive Health with a Gender Perspective, Ministry of Health and Family Welfare Government of the People's Republic of Bangladesh, Sponsored by Sida, UNFPA, Unicef, WHO and World Bank (August 1996).

11. Heise L., Violence Against Women: The Missing Agenda. A chapter in the book 'Women's Health : A Global Perspective, edited by Koblinsky, M.A., Timyan J., Gay J., publisher Westview Press (1992).

12. Hossain, M.S. - Status of Adolescent girls in Bangladesh-1995, Bangladesh, Bureau of Statistics, (BBS), Statistics Division, Ministry of Planning, Dhaka, (September, 1996).

13. Hussain Md. A., Rahman G.S., Begum N., A. Study on Prevalence of RTI/STDs in a Rural Area of Bangladesh. Save the Children (USA), Bangladesh Field Office \& DIPHAM Research \& Service Centre, (September 1996).

14. Islam M.N., Islam M.M., Fertility and Reproductive Health Status of Married Adolescents in Rural Bangladesh, PDEU, Implementation, Monitoring and Evaluation Division (IMED), Ministry of Planning, Government of the People's Republic of Bangladesh, (October 1995). 
15. Kamal N., Streatfield P.K. and Noor A.: "Marital Adolescent Reproductive Health in Bangladesh", Chapter 6 in the extended analysis of the 1993-94 BDHS - Niport and East-West Center (1996).

16. Neaz A., Intersectoral Population Project for Out-of-School Adolescent Girls, Consultancy paper presented to World Bank and UNFPA, Bangladesh (December 1993) .

17. Piet-Pelon N., Reproductive Health In Bangladesh, A Sectoral Review. UNFPA, (April-1996).

18. Program of Action of the 1994 International Conference on Population \& Development, Chapters I-VIII (March 1995).

19. Ross J.L., Chowdhury S.N.M., Mirza T., Health Gender Sexuality-Bangladesh Country Report. ICDDR.B., Special publication No. 50, (July-1996).

20. Waddell A.L., Achieving Reproductive Health for All -, Cairo (1994). The Role of WHO

21. Wasserheit N.J., Harris N.J., Chakraborty J. Kay A.B., Mason J.K. - Reproductive Tract Infections in a Family Planning Population in Rural Bangladesh, Studies in Family Planning, Volume-2, Number-2, Mar/Apr. 1989.

22. Women's Health - Improve our Health - Improve the World, Fourth World Conference on Women, Beijing, China; WHO, Geneva, (September 1995).

23. Zeidenstein S., Moore K., Learning About Sexuality A Practical Beginning. The Population Council \& International Women's Health Coalition, New York, (1996) 